\title{
WestVirginiaUniversity
}

THE RESEARCH REPOSITORY @ WVU

Graduate Theses, Dissertations, and Problem Reports

2009

\section{Efficacy of ultrasound imaging to detect periodontal bone defects}

\author{
Rajia Sebbahi \\ West Virginia University
}

Follow this and additional works at: https://researchrepository.wvu.edu/etd

\section{Recommended Citation}

Sebbahi, Rajia, "Efficacy of ultrasound imaging to detect periodontal bone defects" (2009). Graduate Theses, Dissertations, and Problem Reports. 2783.

https://researchrepository.wvu.edu/etd/2783

This Thesis is protected by copyright and/or related rights. It has been brought to you by the The Research Repository @ WVU with permission from the rights-holder(s). You are free to use this Thesis in any way that is permitted by the copyright and related rights legislation that applies to your use. For other uses you must obtain permission from the rights-holder(s) directly, unless additional rights are indicated by a Creative Commons license in the record and/ or on the work itself. This Thesis has been accepted for inclusion in WVU Graduate Theses, Dissertations, and Problem Reports collection by an authorized administrator of The Research Repository @ WVU. For more information, please contact researchrepository@mail.wvu.edu. 


\title{
Efficacy of Ultrasound Imaging to Detect Periodontal Bone Defects
}

Rajia Sebbahi, D.M.D.

\author{
Thesis submitted to the \\ School of Dentistry \\ at West Virginia University \\ in partial fulfillment of the requirements \\ for the degree of \\ Master of Science \\ in \\ Orthodontics
}
Peter Ngan, D.M.D., Chair
Richard Crout, D.M.D., Ph.D.
Harold Reed, D.D.S.

Department of Orthodontics
Morgantown, West Virginia
2009

Keywords: Ultrasonagraphy, Orthodontics, Periodontics 


\section{ABSTRACT}

\section{Efficacy of Ultrasound Imaging to Detect Periodontal Bone Defects}

Rajia Sebbahi, D.M.D

Objectives: Clinicians are always searching for a non- invasive method to diagnose periodontal defects. Two-dimensional radiographs are limited in the ability to describe a three-dimensional periodontal defect. Ultrasound has been used in dentistry for caries detection and enamel cracks diagnosis. Its non- ionizing radiation properties are attractive to clinical use in dentistry. The purpose of the present study is to investigate the efficacy of ultrasound imaging to accurately detect periodontal defects.

Methods: Twenty mandibles with simulated defects of specific dimensions were imaged using ultrasound and measured. The measurements were compared to the actual defects and to 2-D radiographs measurements. A panel of three evaluators compared ultrasound images of simulated defects to 2- D radiographs of the same defects. 3-D reconstructed images of two mandibles with natural periodontal defects were compared to cone beam images of the same mandibles.

Results: The results have shown that conventional radiographs were not accurate in imaging the posterior mandible, while measurements made from ultrasound images were accurate for both anterior and posterior mandibles. Measurements of the simulated defects from ultrasound images were accurate. The ultrasound images were rated favorably in image clarity, image detail, overall image quality and fatigue level in comparison to conventional radiographs and cone beam imaging

Conclusions: These results suggest that ultrasound imaging may provide a reliable diagnostic alternative to conventional two-dimensional radiographs. Optimizing ultrasound technology for use in dentistry may increase interest in its use. Enough interest exists for further clinical evaluation. 


\section{DEDICATIONS}

This thesis is dedicated to my daughter Layla , my husband and best friend Hani and my parents who have always encourage and support me.

Thank you for your unwavering support and giving me the opportunity to learn and grow. I will always be grateful. 


\section{ACKNOWLEDGEMENTS}

\section{A special thanks are extended to the following individuals:}

Dr. Peter Ngan for your invaluable guidance, encouragement, and inspiration and for spending the individual time away from work to help me with my thesis.

Dr. Ricahrd Crout for serving on my thesis committee and the exceptional editing. Your precious time to be evaluator on an integral part of my thesis was greatly appreciated.

Dr. Harold Reed for serving on my thesis committee and your unique insight and ideas on my project and giving your precious time to be evaluator on an integral part of my thesis.

Drs. John Dempsey, Jeff Gilmore, Jennifer Hamilton, Mike Hazey,, Kerry Kirsch, Thomas Jarrett, Chris Martin, Edward McFarland, and Tim Tremont, for all the invaluable lessons and clinical knowledge that you have provided me. I have learned so much from all of you and am thankful that I was enabled the opportunity to work with each of you.

Dr Joe Bonello, for all your advice and priceless knowledge. I will always remember you

Pam , Karen and Leona, for your support and keeping us in check in the clinic. We could not do it without you guys. Thanks for all the good times and good laughs.

Joyce and Carrie, for your help and support in everything. You are an asset to this program and I am so thankful to have gotten the opportunity to work with you.

Drs. Michael Becht and Dr. Thuy Do- Delatour, my classmates. I do not think I could have made it through with out you. You made the program much more bearable. Thank you for all your help. You were true friends indeed. I will miss you so much.

The Residents: Mike, Dean, Kolin, Maggie , Erica and Rob for making the last two years of my residency truly enjoyable. 


\section{TABLE OF CONTENTS}

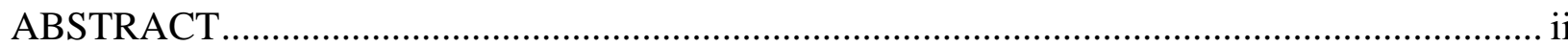

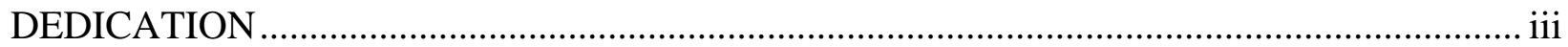

ACKNOWLEDGEMENTS .......................................................................................... iv

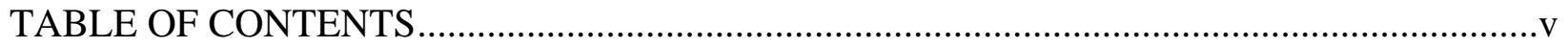

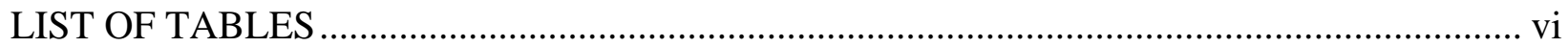

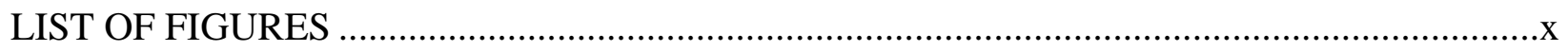

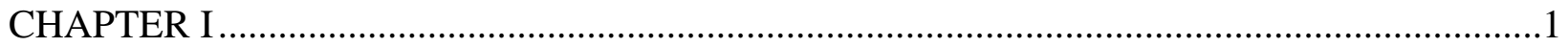

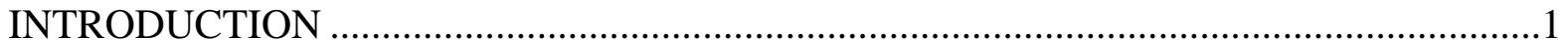

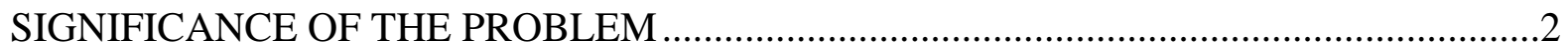

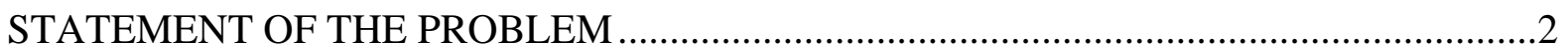

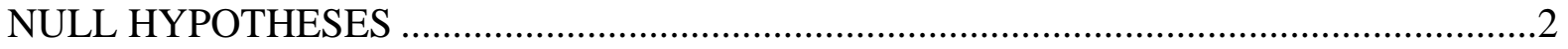

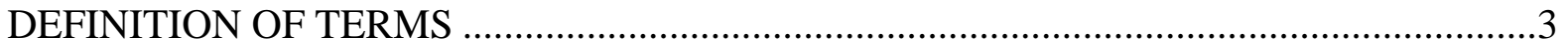

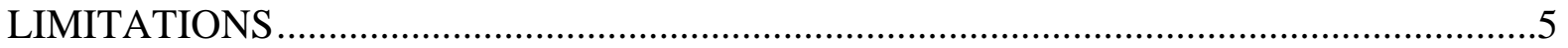

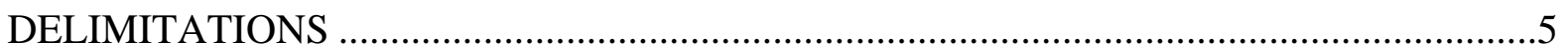

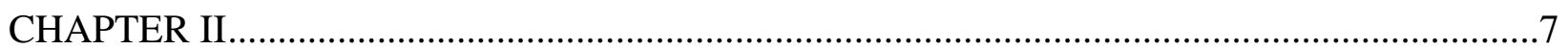

REVIEW OF LITERATURE …………………………...............................................

CLASSIFICATION OF PERIODONTAL DEFECTS............................................................

ORTHODONTIC TREATMENT OF PERIODONTAL DEFECTS .......................................

RADIOGRAPHIC DETECTION OF PERIODONTAL DEFECTS ………............................

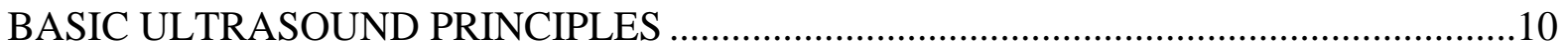

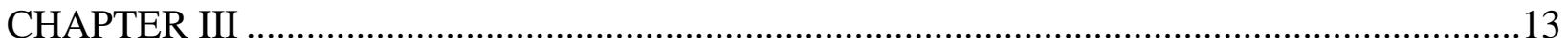

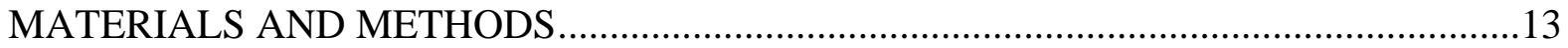

EDENTULOUS DRIED CADAVER MANDIBLE PHASE:

Simulated Periodontal Bone Defects ...................................................................14

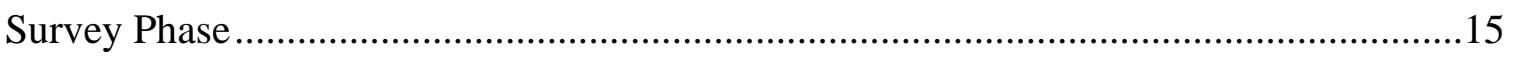

DENTATE DRIED CADAVER MANDIBLE PHASE: Natural Periodontal Defects............16

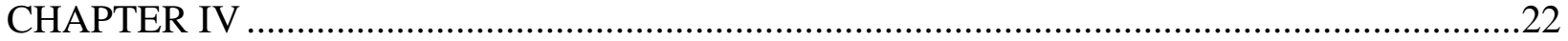

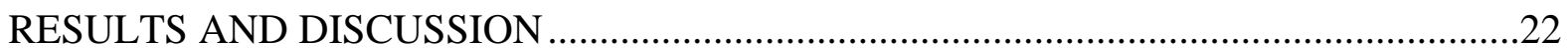

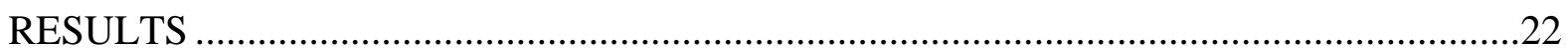

EDENTULOUS DRIED CADAVER MANDIBLE PHASE ..................................................22

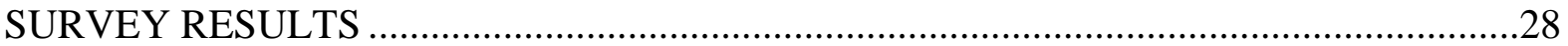

DENTATE DRIED CADAVER MANDIBLE PHASE .......................................................31

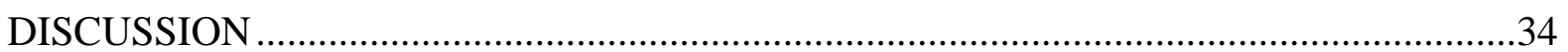

EDENTULOUS DRIED CADAVER MANDIBLE PHASE ...............................................34

DENTATE DRIED CADAVER MANDIBLE PHASE ...........................................................37

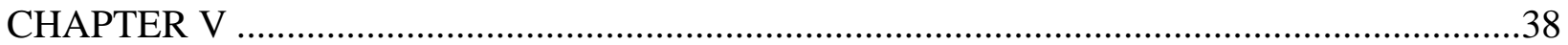

SUMMARY, CONCLUSIONS, RECOMMENDATIONS ……........................................38

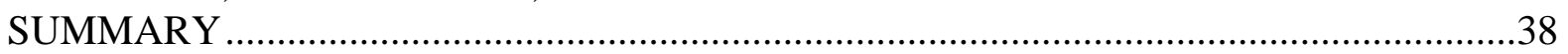

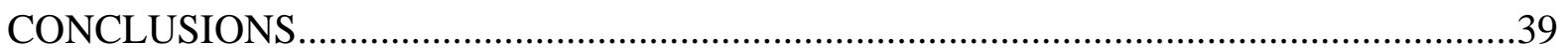

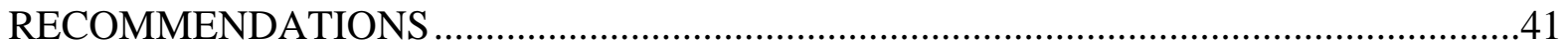

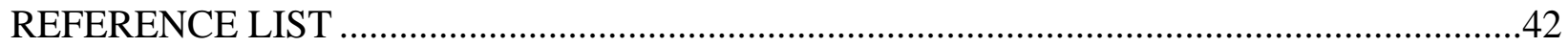

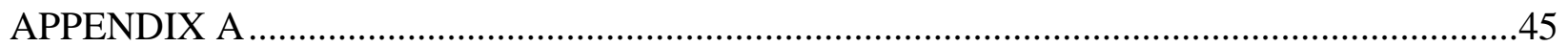

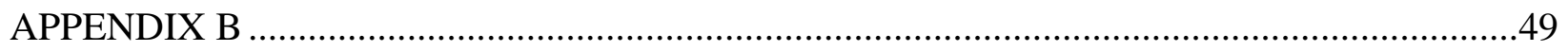

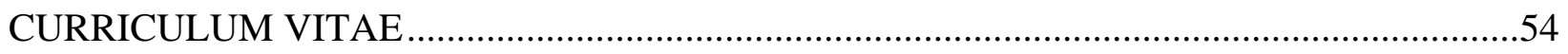




\section{LIST OF TABLES}

Table 1: Comparison between actual diameter and measurements made using the conventional 2-D x-ray with different exposure time and angulation A: anterior, LB: left buccal, RB: right buccal.

Table 2: Comparison between actual diameter of defects and measurements made using ultrasound

Table 3: Comparison between measurements of defects using ultrasound and 2-D radiographs at different exposure time and angulation

Table 4: Comparison of ultrasound based on defect size in anterior region..................................26

Table 5. Comparison of ultrasound based on defect size in the left buccal region..........................26

Table 6. Comparison of ultrasound based on defect size in the right buccal region .......................26

Table 7. Comparison of ultrasound to actual defects based on defect size using Tukey -Kramer.

Table 8. Comparison of conventional based on defect size in anterior region ...............................27

Table 9. Comparison of conventional based on defect size in left buccal region..........................27

Table 10. Comparison of conventional based on defect size in right buccal region .....................28

Table 11. Comparison of conventional to actual defects based on defect size using TukeyKramer. .28

\section{LIST OF FIGURES}

Figure 1. Comparison of quality of image between ultrasound and radiographs .......................29

Figure 2. Comparison of fatigue level between ultrasound and radiographs ..............................31

Figure 3. Image preferences between ultrasound and radiographs..........................................32

Figure 4. Comparison of quality of image between ultrasound and cone beam.........................33

Figure 5. Comparison of fatigue level between ultrasound and radiographs .............................33

Figure 6. Image preferences between ultrasound and cone beam ............................................34 


\section{CHAPTER I \\ INTRODUCTION}

Orthodontists are routinely involved in the treatment of periodontal bony defects. Molar uprighting and forced eruption are examples of procedures undertaken by orthodontists to treat periodontal defects. In addition, the presence of a defect may alter an orthodontic treatment plan. Therefore, accurate detection and diagnosis of such defects is important in prescribing the proper orthodontic treatment. Although, the Golden standard in diagnosing periodontal defects is intrasurgical measurements ${ }^{1}$, it has the drawback of being an invasive procedure. Therefore, indirect means to detect periodontal defects are utilized, including periodontal probing and radiographic measurements. The limitations of periodontal probing are related to the operator such as positional errors and the force used when probing a pocket, and/or the periodontal probe diameter and shape of the probe. ${ }^{2}$ The use of radiographs can help in diagnosing periodontal defects, previous studies have shown the inability of traditional two-dimensional radiographs to adequately describe a three-dimensional periodontal defect when compared to the gold standard of intrasurgical measurement. Ionizing radiation is the major problem with radiography. It causes chemical changes in the irradiated cells, yielding to possible biologic damage. Jeffcoat et $\mathrm{al}^{3}$ found that radiation burden is low. Radiographs are also two dimensional representation of complex three dimensional bone, tooth and soft tissue structures. ${ }^{3}$ Three dimensional radiographs are more accurate in discerning the type of periodontal defects such as two-wall or three wall periodontal defects. However, the cost is high and they are not usually available in every office. Ultrasound is a promising technology that can be used to detect quantitively bone density. Its non-ionizing radiation properties are attractive to clinical use in dentistry. The first use of diagnostic ultrasound in dentistry have been by Baum et $\mathrm{al}^{4,5}$ who used a borrowed $15 \mathrm{MHz}$ 
ophthalmological ultrasound scanner to image the internal structure of teeth. ${ }^{4}$ Spranger in1971 reported use of ultrasound to diagnose marginal periodontal disease. ${ }^{6}$ The use of ultrasound to diagnose bony defects has not been reported in the literature. The objective of this study was to investigate the efficacy of ultrasound imaging in diagnosing periodontal bony defects.

\section{Significance of the Problem}

Clinicians are always searching for a non- invasive method to diagnose periodontal defects.

Two-dimensional radiographs are limited in the ability to describe a three-dimensional periodontal defect when compared to the gold standard of intrasurgical measurement. The purpose of the present study is to investigate the efficacy of ultrasound imaging to accurately detect periodontal defects.

\section{Statement of the Problem}

Does ultrasound provide more information and accurate image of a periodontal defect, compared to traditional 2-D radiograph?

\section{Null Hypothesis}

\section{Comparison of ultrasound and conventional radiographs using simulated periodontal defects}

1. No significant difference exists between accuracy of measurements obtained from ultrasound images and conventional 2-D radiographs when the width of defect was varied. 
2. No significant difference exists between accuracy of measurements obtained from ultrasound images and conventional 2-D radiographs when the exposure time was varied.

3. No significant difference exists between accuracy of measurements obtained from ultrasound images and conventional 2-D radiographs when the beam angulation was varied.

4. No significant difference exists between accuracy of measurements obtained from ultrasound images and 2-D radiographs when bone density (anterior and posterior part of the mandible) was varied.

\section{Comparison of ultrasound and conventional radiographs using natural periodontal defects}

1. No significant difference exists in the levels of image clarity, image detail, overall image quality, and fatigue levels between 2-D ultrasound images and conventional 2-D radiographs.

2. No significant difference exists in the levels of image clarity, image detail, overall image quality, and fatigue levels between 3-D ultrasound images and 3-D Cone beam images.

\section{Definition of Terms}

1. Ultrasound - acoustic energy in the form of waves having a frequency above the human hearing range

2. Conventional radiography - the use of $x$-ray film and an $x$-ray machine to produce a radiograph of a specified hard tissue structure.

3. Periodontal Defect - an area of bone loss in supporting alveolar bone.

4. Soft Tissue Phantom - a material that accurately simulates the density and $\mathrm{x}$-ray scattering properties of human soft tissue in experiments involving radiography. 
5. Transducer - generates and receives high frequency sound waves. Crystals inside the transducer emit pulses of sound waves.

6. Sonix ultrasound - Sonix RP manufactured by Ultrasonic medical Corp., BC, and Canada.

7. Exposure Time - the amount of time measured in seconds or fractions of seconds that an object is exposed to an $\mathrm{x}$-ray beam. A main determinant of radiographic density.

8. Bone Quality - A description of bone structure which includes the relative amounts and density of cortical and trabecular bone.

9. Cone-Beam Computed Tomography - the rotation of the x-ray producing tube head around the patient producing 365 slices as axial projection data that is reconstructed into a 3-D image by computer

10. X-ray Beam Angulation - the angle of application of an x-ray beam upon an object measured in both the horizontal and vertical direction.

11. 2-D - Two Dimensional

12. 3-D - Three Dimensional

13. Radiographic Image Detail - A qualitative measure of how much information an evaluator gets from an image.

14. Overall Radiographic Image Quality - Characteristic of radiographs involving contrast, density, sharpness, and object positioning.

15. Fatigue Level - How long an evaluator had to view an image when evaluating the image.

16. Anisotropic - exhibiting properties with different values when measured in different directions. 


\section{Limitations}

1. The available ultrasound imaging for this study is optimized for soft tissue, thus images of hard tissue-bone may not be optimal.

2. Ultrasound waves do not travel well through air or bone.

3. Dried cadaver mandibles do not fully substitute for living, biologic bone. The characteristics of dried bone are different than that of living bone.

4. Ultrasound produces a new type of image, which a panel of investigators will not be familiar with viewing. Anisotropy of teeth and their complex geometries may lead to variations in measurements depending in the position and direction of the beam

5. Anisotropy of teeth and their complex geometries may lead to variations in measurements depending in the position and direction of the beam.

6. The principal investigator will choose the settings and the angulation of the ultrasound transducer that produce the most useful image. It is possible that different settings may alter the image quality of individual ultrasound images.

\section{Delimitations}

1. Ultrasound transducer angulation will not be studied.

2. The study will be limited to the dental practitioner's perception of ultrasound usefulness in dental imaging. Image detail, clarity, quality, as well as confidence and fatigue levels will be evaluated.

3. The simulated periodontal defects are made in symmetrical manner. The actual defects may have irregular shapes. 
4. The variables of the study will be limited to exposure time, beam angulation, differing bone density/quality between anterior and posterior mandibular regions, and different defect size.

5. One researcher performed all of the radiographic procedures.

6. One researcher performed all of ultrasound imaging.

7. One researcher performed all of the radiographic and rendering defect measurements. 


\section{CHAPTER II}

\section{REVIEW OF LITERATURE}

\section{Classification of Periodontal Defects}

Changes in alveolar bone around teeth are important information to orthodontists because excessive loss of alveolar bone will ultimately be responsible for tooth loss. A periodontal defect is defined as an osseous defect in the supporting alveolar bone. Periodontal defects can take on many forms. A horizontal defect, the result of what is often referred to as horizontal bone loss, is the most common pattern of bone loss. The bone level is reduced in a more or less even pattern with the bony margin remaining perpendicular to the tooth surface. The bone level is also relatively parallel to the cemento-enamel junctions of adjacent teeth. The vertical or angular defect is another type of periodontal defect. This bone loss pattern occurs in an oblique direction and leaves a hollowed-out trough in bone adjacent to the tooth root. These defects can also occur on facial or lingual/palatal surfaces of bone. Goldman and Cohen classified vertical defects based on the number of bony walls intact. By this classification, it is possible to have a one, two or three-walled defect. Three-walled defects are often referred to as infrabony defects. ${ }^{7}$

Types of vertical periodontal defects: A) 3-walled, B) 2-walled, C) 1-walled

Vertical defects are most commonly encountered in orthodontics. These types of defects are encountered with mesially tilted posterior teeth and cases of localized periodontal disease. The diagnosis of vertical periodontal defects is important for the orthodontist as he or she attempts to form a treatment plan to either avoid or treat the periodontal defect through orthodontics. Furthermore, the orthodontist would like to have a visual image of the topography and dimensions of the defect to properly prescribe treatment. The radiograph is commonly used to provide this image. 
The dimensions of a vertical defect are considerably more difficult to determine radiographically than horizontal defects and often require careful probing and/or surgical exposure for confirmation. The shortcomings of traditional radiography in imaging vertical defects often lies in the presence of thick buccal and lingual cortical plates that obscure the defect. This thick cortical plate often does not allow an accurate radiographic image of the defect as the plate decreases the number of $\mathrm{x}$-rays that are able to irradiate the defect and produce an image. Studies have shown that traditional radiographs can significantly underestimate the amount of interproximal bone loss that is actually present in up to \%71 of cases. ${ }^{8}$

\section{Orthodontic Treatment of Periodontal Defects}

The mesial tilting of posterior teeth as a result of loss of arch integrity due to extractions, extensive caries, or ectopic tooth eruption is a common problem in adult orthodontic patients. The tilted position of these posterior teeth impairs the patient's ability to maintain good oral hygiene and can lead to occlusal trauma as forces are no longer directed down the long axis of the tooth. This compromised tooth position also makes adequate restoration of the teeth difficult and sometimes impossible. These factors, along with the presence of dental plaque bacteria, can promote the formation of intraosseous periodontal defects. ${ }^{9}$ Orthodontic treatment is a viable option for a means of attaining a more favorable osseous contour in some cases with periodontal defects. This means of treatment is especially advocated in a one-walled defect in which the predictability of regenerative periodontal therapy is very low. ${ }^{10}$ Various orthodontic movements such as intrusion, extrusion, moving a tooth toward the defect, and moving the tooth away from the defect can modify the osseous contour. ${ }^{11,12}$ Molar uprighting, frequently reduces or eliminates the periodontal defect without any need for regenerative periodontal therapy. ${ }^{13-15}$ Cirelli, et al. concluded that orthodontic movement did not interfere with the healing process of 
one-walled intraosseous periodontal defects. ${ }^{9}$ Polson, et al. ${ }^{12}$ and Lindskog-Stokland, et al. ${ }^{16}$ found similar results in their investigation of tooth movement towards periodontal defects. Ericsson, et al. ${ }^{19}$ and Garaci, et al. ${ }^{17}$ reported an increase in the connective tissue attachment levels after performing mesial inclination and bodily movement of teeth toward such defects. Therefore, orthodontic tooth movement may enhance the healing process and the periodontal condition in certain cases.

In other cases, orthodontic treatment is not advocated for correcting periodontal defects in active periodontal disease. If the inflammation from periodontal disease is not arrested prior to orthodontic tooth movement, the situation will worsen. Orthodontic tooth movement is itself an inflammatory process. Orthodontic inflammation in addition to already present periodontal inflammation can result in a more rapid periodontal destruction. ${ }^{18}$

Orthodontics is not advocated in the treatment of periodontal defects in the presence of a three-walled vertical defect. A three-walled vertical defect is best treated using an osseous regenerative procedure. ${ }^{19}$ The rationale behind this treatment plan is the fact that a three-walled defect has enough bony support to hold a bone graft is place. In addition, the higher the number of bony walls present, the greater the supply of cells for regeneration. ${ }^{13}$ This situation would not be true for a one- or two-walled defect, which would not as easily hold a bone graft and would have less surface area from which to provide cells for regeneration.

At any rate, the possibility of successful orthodontic treatment of periodontal defects increases the need for more accurate detection and diagnostic procedures.

\section{Radiographic Detection of Periodontal Defects}

The detection and accurate assessment of the location, extent, and configuration of the periodontal defect is important for the determination of the tooth prognosis, treatment plan, and 
the maintenance procedures. ${ }^{20}$ When it comes to the detection and diagnosis of periodontal defects, many methods can be used. Manual probing to discern the borders and dimensions of the defect is the most acceptable clinical assessment of periodontal inflammation. ${ }^{7}$ Radiography is used in an attempt to supplement the manual probing and provide a picture of the defect. The gold standard for in-depth description of a defect's dimensions is intrasurgical measurement. ${ }^{1,8 \text {, }}$

${ }^{21}$ only by this method can the clinician see the topography and extent of the defect in its entirety. Obviously, the intrasurgical measurement procedure is the most invasive, costly, and timeconsuming. In addition, manual probing is very technique sensitive and is difficult to standardize between clinicians. Therefore, increasing emphasis is placed on radiography for the detection and description of periodontal defects. However, the effectiveness of radiography for this purpose has been less than ideal. Studies have shown that that traditional radiographs can significantly underestimate interproximal bone loss. ${ }^{22,}{ }^{23}$ Early periodontal lesions are not detected in radiographs. ${ }^{24}$ The loss of bone is masked with cortical plates that initially remain intact. $^{25}$

\section{Basic Ultrasound Principles}

Ultrasound refers to sound waves beyond the human audible range. Diagnostics applications of ultrasound use frequencies of 1 to 10 million cycles/ sec, or 1 to $10 \mathrm{MHz}$ Ultrasound are used to examine soft tissue anatomic structures. In medical ultrasound, the vibrating source is a ceramic element that vibrates in response to an electrical signal. The vibrating motion of the ceramic element in the transducer causes the particles in the surrounding tissue to vibrate. The transducer converts electrical energy to mechanical energy. The difference between ionizing radiation and ultrasound is that to increase the intensity of a beam of X-ray of a given spectral distribution, one increases the photon flux. The energy of individual photons 
remains unchanged. The interaction mechanism of each photon remains the same but the number of interactions increases. To increase the intensity in a beam of ultrasound of fixed frequency, one increases the amplitude of particles to obtain a higher energy flux per unit area. ${ }^{26}$

In diagnosing periodontal disease using ultrasonography, the most common approach is using a pulse-echo probe that transmits the ultrasonic pulse at the gingival pocket through a coupling medium such as water. ${ }^{27}$ The ultrasound energy reflects from the periodontal ligament and is received by the transducer. Then because the speed of sound is constant, the distance to the periodontal ligament can be calculated. Second method involves transmission. It aims the ultrasonic energy at the gingival and has a separate receiving transducer inside the mouth to receive the signal. A third way involves applying a contact transducer to the gingival with some impedance- matching layer, such as rubber or ultrasonic gel pads. A B scan then can be produced similar to medical diagnostic practice. ${ }^{27}$

In evaluating alveolar crest, both Greenberger al and Ursell ${ }^{28}$ concluded that transgingival probing or bone sounding was an accurate clinical estimator of alveolar bone levels. Tsiolis ${ }^{5}$ et al shows that ultrasonography which is less invasive than transgingival probing, can provide more accurate and repeatable estimation of the level of alveolar bone crest. His study has demonstrated that ultrasonography can produce images at buccal sites suitable for assessment of the periodontal structures. Measurements of certain landmarks revealed that ultrasonic scanner provided satisfactory results, both in terms of accuracy and repeatability. Moreover, ultrasound measurements were in better agreement with direct probing measurement than the agreement of the transgingival probing with direct measurement. ${ }^{5}$ Lost et al(1988) were able to determine the width of the periodontal ligament, using one dimensional A-scans in pig jaws. They also achieved the determination of the facial/ oral alveolar crest of pigs with one dimensional RF- 
echograms .Lost et al(1989) reported on ultrasonics B-scans for two dimensional images of the oral/facial alveolar crest of pigs and concluded that the $20 \mathrm{MHz}$ tranducer was more accurate than the $10 \mathrm{MHz}$, due to better image resolution. They also concluded that the alveolar bone crest could always be determined. $^{29}$ 


\section{CHAPTER III}

\section{MATERIALS AND METHODS}

The study will investigate diagnosis of natural periodontal defects and simulated defects in dried cadaver mandibles. The defects were radiographed in a previous study and those radiographs will be used for comparison. ${ }^{30}$ The same mandibles will be immersed in distilled water and will be imaged using Ultrasound waves applied through a handheld scanner called transducer probe. All the mandibles are immersed in water to assure the efficient coupling. The transducer probe will be randomly moved around the defect to obtain the most accurate image. The diameter of each defect placed in the cortical bone of the lateral surface of the mandibles was measured at its widest dimension in millimeters on the conventional radiograph and the ultrasound image. These measurements were entered into a Microsoft Excel spreadsheet. The measurement using ultrasound will be compared for accuracy to radiographic images

Twenty dried human cadaver mandibles will be used. Two dentate with existing natural periodontal defects will be imaged using 3- D ultrasound and cone beam. Each mandible is assigned a number for identification. The picture below shows the Sonix RP ultrasound system that will be used. It is a diagnostic ultrasound unit with special research capabilities, used with its 5-14 MHZ linear array ultrasound transducer. The machine is used in the clinical mode for dry

mandible examination to provide B-mode processed image. The radio frequency signals reflected from the field of view are digitized using sampling frequency of $40 \mathrm{MHZ}$ 


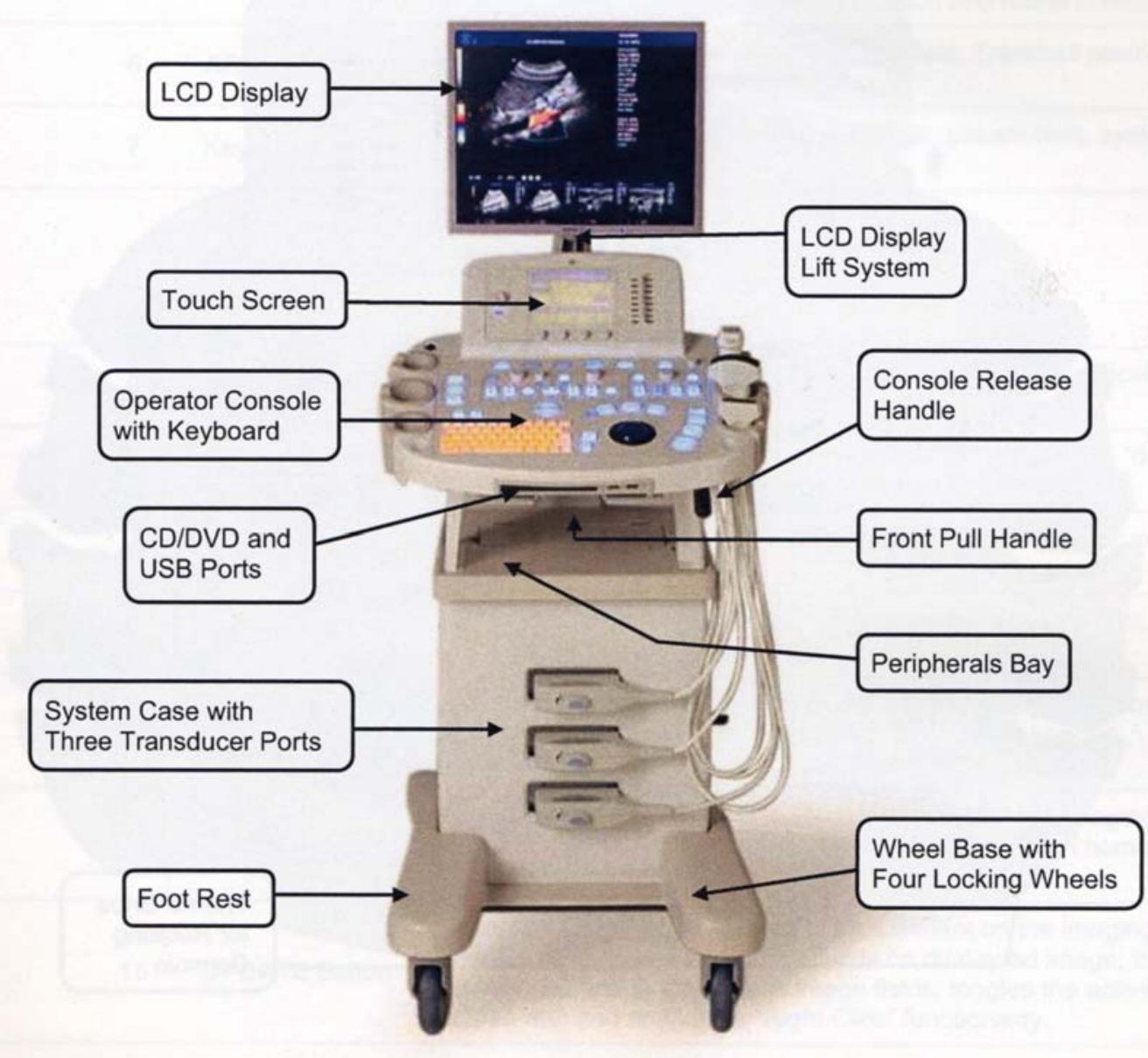

\section{The Edentulous Mandibles with Simulated Periodontal Defects}

The edentulous specimens have various simulated bony defects. The stimulated defects were made in anterior and lateral posterior using a custom drill press and various sizes of drill bits the first row of defects was intracortical, placed in random order on the superior surface of mandibular bone with a uniform depth of $6 \mathrm{~mm}$, and had the following diameters: $1 \mathrm{~mm}, 2 \mathrm{~mm}$, and $4 \mathrm{~mm}$. A second row of defects penetrated the cortical bone on the lateral surface of the mandible, had a uniform depth of 3mm, and had the diameters previously mentioned placed in random order. Figure A illustrates the configuration of the simulated defects. ${ }^{30}$ 


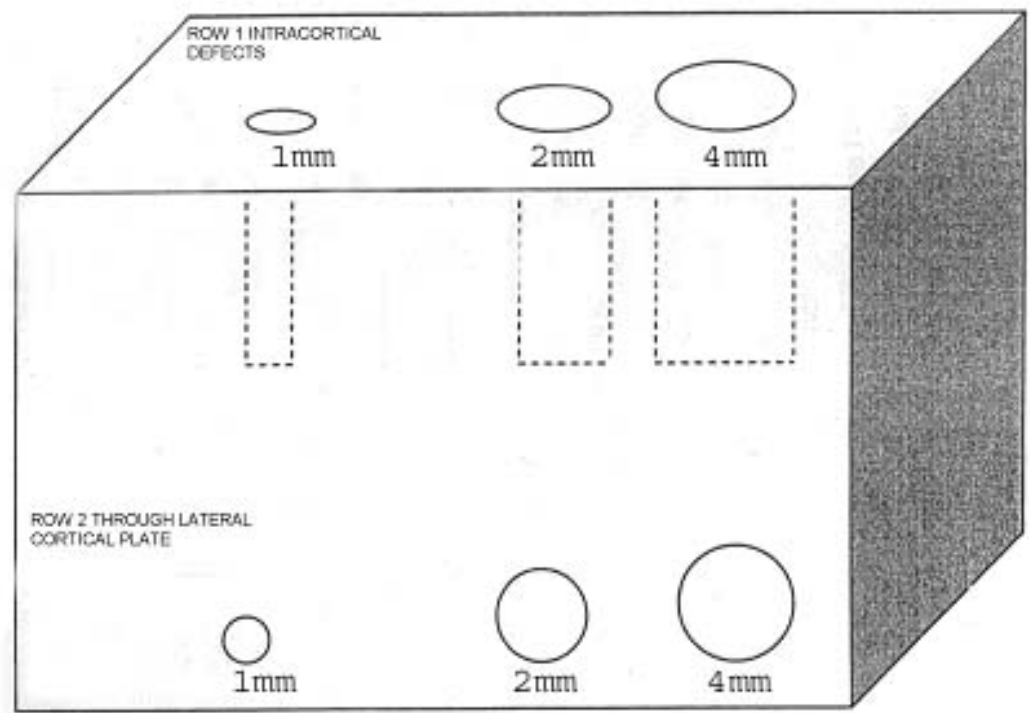

Figure A. Simulated periodontal defect arrangement (note: actual arrangement was randomized)

The defects will be imaged using Sonix ultrasound and the width of each defect will be measured at the widest dimension in millimeters. These measurements will be compared for accuracy to measurement obtained using traditional X-rays. The depth of the defects will not be imaged with ultrasound due to limitations of the sonix machine available for use. . The diameter of each defect will be measured at the widest dimension in millimeters. These measurements will be statistically compared to measurement of the same defects obtained using traditional Xray.

\section{Survey Phase}

Ten ultrasound images will be compared to ten conventional radiographs of the same simulated defects. The images were kept in their original sizes. A panel of three clinicians will evaluate the images and fill up a questionnaire reporting the quality, fatigue level, overall clarity and their preference. A copy of the questionnaire is located in Appendix A 


\section{The Dentate Mandible with Natural Periodontal Defect}

Existing periodontal defects in two mandibles will be imaged using high frequency ultrasound and a 3-D reconstructed image will be generated. The 3-D reconstructed image will be compared to images generated with cone Beam CT . The ultrasound system in this part of study employs high frequency single-element ultrasound focused transducers (15 and $30 \mathrm{MHz}$ ) for scanning. The following technical information about image acquisition and processing is adapted from Ahmed Mahmoud in his paper titled "High frequency 3D echodentographic imaging modality for early assessment of periodontal diseases: in vitro study”. ${ }^{31}$ Continuous acquisition using an I GHz data acquisition card is synchronized with a high precision twodimensional stage positioning system of $\pm \mathrm{l}$ p-m resolution for acquiring accurate and quantitative measurements of the mandible in vitro. Radio frequency (RF) signals are acquired laterally $45.5 \sim \mathrm{m}$ apart for each frame. Different frames are reconstructed $500 \sim \mathrm{m}$ apart for the 3D reconstruction. Signal processing algorithms are applied on the received ultrasound signals for filtering, focusing, and envelope detection before frame reconstruction. Then edge detection technique is adopted to detect the bone surface in each frame. All edges are combined together to render a 3D surface image of the jawbone. 


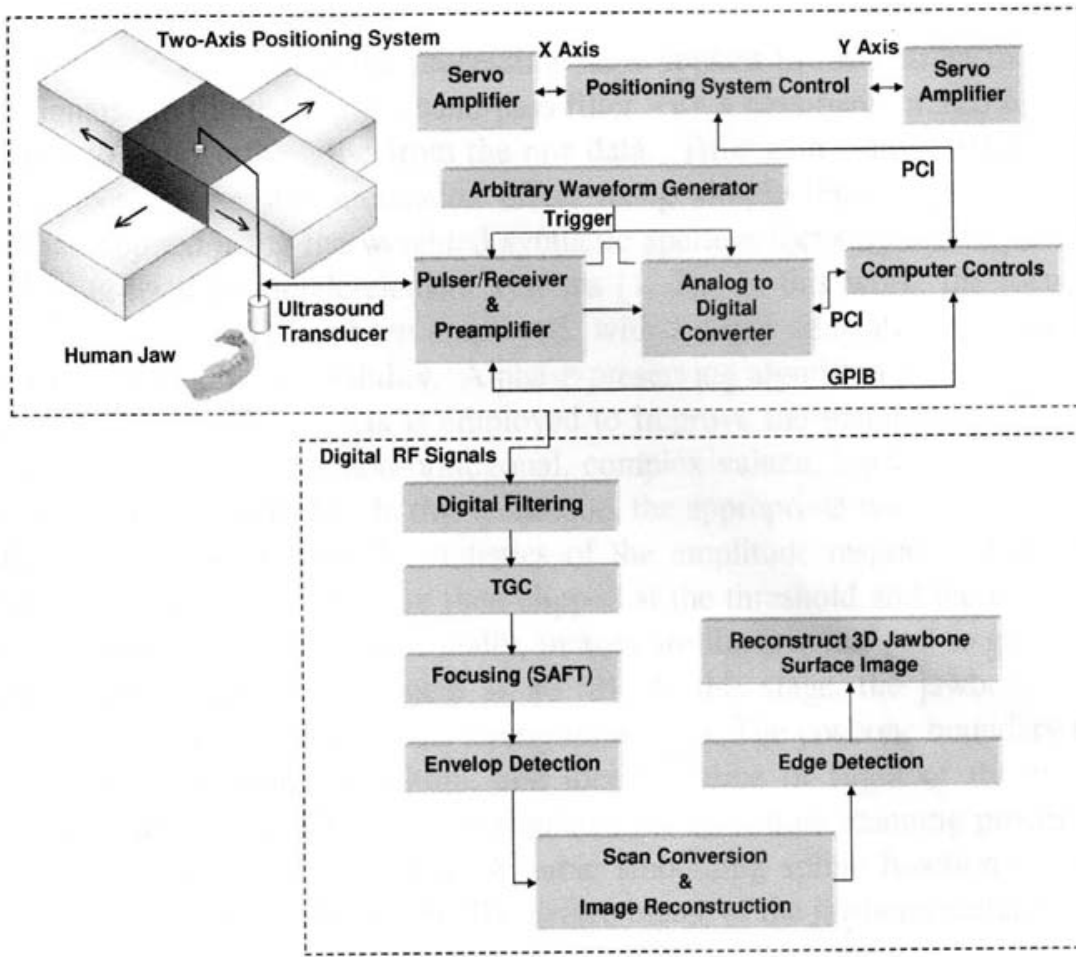

Figure 1. Schematic diagram showing the design and processing steps of the high-freque system for jawbone.

\section{System Drawing}

Figure 1 show a schematic diagram of the high frequency ultrasound imaging system. The upper part explores the main component of the system. A main bang of negative impulse type is used as the excitation signal for the ultrasound transducer. This signal is generated and amplified using a general purpose ultrasonic pulser-receiver.

The same ultrasound transducer is used as both ultrasound transmitter and receiver and is connected to transmit/receive the port of the ultrasound pulser-receiver, which is operated in the pulse-echo mode. Two single-element ultrasound transducers are used (15 and $30 \mathrm{MHz}$ ). This echo signal is then amplified and filtered by the ultrasonic pulser-receiver. The filtered and amplified signal is fed to a high-speed waveform digitizer which is synchronized with the 
excitation signal. The imaging system uses a high performance PC based system for system control, synchronization, and for further signal processing . The PC controls a two-axis precision positioning system with I $\sim \mathrm{m}$ resolution. The positioning system is synchronized with the data acquisition to collect the ultrasound signals continuously on the flight during the transducer

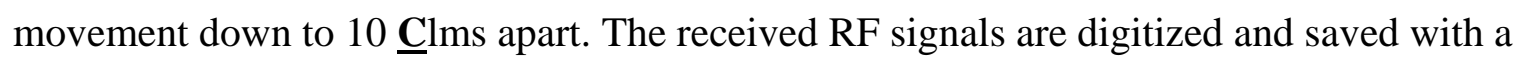
sampling rate of $62.5 \mathrm{MHz}$ as an 8-bits word using a high-speed data acquisition board. The high speed data acquisition board is fully controlled with the main PC via the PCI bus. A custom user-friendly computer program designed with Labview 8.2 (National Instruments, Austin, TX, USA) is used to control both the data acquisition board and the positioning system. These signals are saved sequentially according to the lateral location for further post-processing. The data is then transferred to Matlab7.1 (The MathWorks, Inc., Natick, MA, USA) for post processing and image reconstruction. ${ }^{31}$

\section{Signal and Image Processing}

Raw signals are filtered using a band-pass filter with a pass-band of $\pm 20 \%$ of the transducer center frequency to remove the noise from the raw data. Time gain control (TGC) is applied after filtration to compensate for the attenuation effect using simple linear functions. The focusing procedure is then applied using the weighted synthetic aperture focusing technique (SAFT), which has been widely utilized for single-element systems. In this work, the focusing technique described by Frazier et al. has been employed with a slight adaptation to assure homogenous focusing due to its simplicity and validity. A phase-preserving algorithm based on decomposing the signal using complex-valued wavelets is employed to improve the image quality and decrease the noise . This algorithm utilizes non-orthogonal, complex valued, logGabor wavelets to convert the image to the transform domain. In this technique, the appropriate 
wavelet shrinkage thresholds are automatically determined from the statistics of the amplitude response of the smallest scale wavelet quadrature pair. Transforms are then clipped at the threshold and the inverse transform is taken for optimal image improvement. Finally, images are linearly mapped to gray scale levels for display at the proper dynamic range such as $80 \mathrm{~dB}$. At this stage, the jawbone outer boundary appears brighter than any object due to the strong reflections. The jawbone boundary is detected via applying an image thresholding algorithm, and then the time of flight of the first boundary is recorded for each scan line. A 3D mesh is formulated for the whole scanning process consisting of the recorded arrival times for each frame. A cubic smoothing spline function is then utilized to smooth the 3D mesh, before displaying the 3D surface image of the jawbone surface. An image of using the high frequency ultrasound focused transducers is illustrated in Figure B. ${ }^{31}$ 

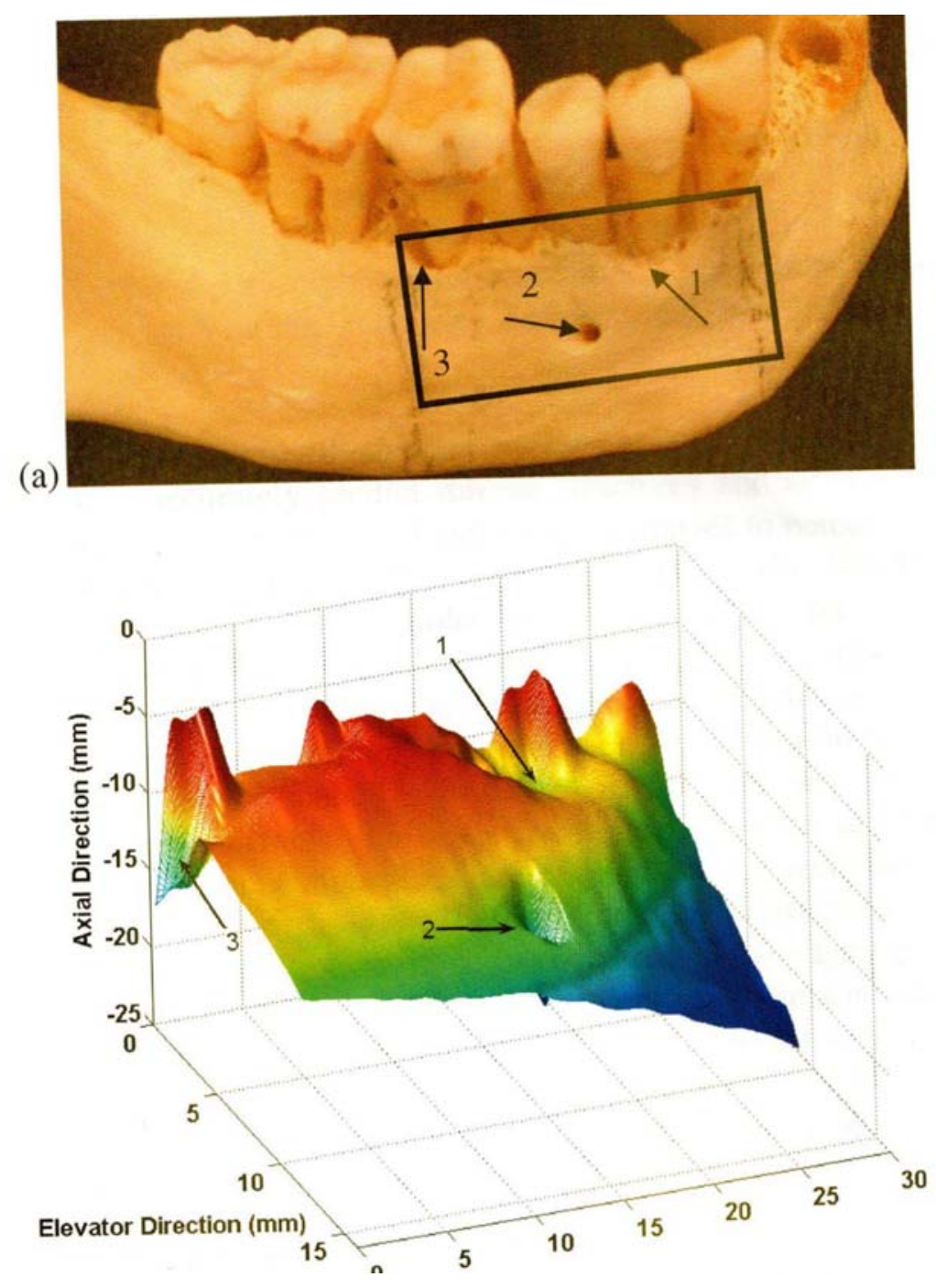

Figure B: a) Photographic image for the mandible with a rectangle showing the scanned region and three landmarks. b)3D ultrasound surface image for the jaw bone surface ${ }^{31}$ 


\section{Data Analysis}

Data will be organized using Excel spreadsheet.

ANOVA, Student's t-test, and Least Squares Means tests will be used to analyze data. The pvalue will be set to 0.05 for $95 \%$ significance.

\section{Statistical Analysis}

To analyze the data, a data table was set up in Microsoft Excel. The columns were labeled "conventional radiograph diameter” or Ultrasound diameter”. The rows were labeled with the mandible identification number and defect location. Each defect dimensional measurement was entered in the corresponding cell. The difference between the ultrasound and the actual defect measurement, the conventional radiograph and the actual defect were calculated using one way analysis. The difference between the ultrasound and the 2-D conventional radiographic measurements were calculated using the ANOVA test. These differences were evaluated based on variables, which included: defect location in the mandible, defect size. X-ray beam exposure time and angulation of the conventional radiographs. P-values based on $95 \%$ significance were calculated as well.

True Value: Three drilled defects of sizes $1 \mathrm{~mm}, 2 \mathrm{~mm}$, and $4 \mathrm{~mm}$ 


\section{CHAPTER IV \\ RESULTS AND DISCUSSION}

\section{RESULTS}

\section{The Edentulous Mandibles with Simulated Periodontal Defects}

Table 1 shows the comparison between the actual defect diameters of $1 \mathrm{~mm}, 2 \mathrm{~mm}$ and 4 $\mathrm{mm}$ to measurements obtained using conventional 2- D radiographs in anterior and posterior locations. Exposure time and angulation of the x-ray beam were varied as follows: 12 impulses+90 degrees , 10 degrees and 20 degrees,18 impulses+ 90 degrees, 8 impulses,90 degrees. $\mathrm{P}$ value was less than 0.001 in the right buccal and left buccal for all the variables in angulation and time exposure. There was statistically significant difference between measurements made using radiographs in the left and right posterior area of the mandibles. No significance difference was found in the measurements made in the anterior. 
Table 1: Comparison between actual diameter and measurements made using the conventional 2-D x-ray with different exposure time and angulation A: anterior, LB: left buccal, RB: right buccal

\begin{tabular}{|c|c|c|c|c|}
\hline & Area & $\begin{array}{c}\text { Mean } \\
\text { difference } \\
\text { true value- } \\
\text { Conv) }\end{array}$ & $\begin{array}{c}\text { Standard } \\
\text { Error of } \\
\text { the } \\
\text { Difference }\end{array}$ & P value \\
\hline $\begin{array}{c}\text { 12 impulses+90 } \\
\text { degrees }\end{array}$ & A & -0.100 & 0.05 & 0.07 \\
\hline 12 impulses+10 & A & -0.195 & 0.03 & 0.00 \\
degrees & LB & -0.222 & 0.03 & 0.00 \\
\hline 18 impulses+ 90 & A & -0.087 & 0.06 & 0.20 \\
degrees & LB & -0.151 & 0.03 & 0.00 \\
& RB & -0.186 & 0.03 & 0.03 \\
\hline 12 impulses +20 & A & 0.087 & 0.09 & 0.37 \\
degrees & LB & -0.219 & 0.05 & 0.00 \\
& RB & -0.303 & 0.04 & 0.00 \\
\hline $\begin{array}{c}\text { 8 impulses,90 } \\
\text { degrees }\end{array}$ & A & $\mathbf{0 . 0 3 7}$ & 0.06 & 0.53 \\
& LB & -0.386 & 0.14 & 0.01 \\
& RB & -0.185 & 0.04 & 0.00 \\
\hline & & & 0.03 \\
\hline
\end{tabular}


Table 2 shows the comparison between the actual defect diameters of $1 \mathrm{~mm}, 2 \mathrm{~mm}$ and 4 $\mathrm{mm}$ to measurements obtained using ultrasound in anterior and posterior locations. There was no statistically significant difference between the actual diameter of defects and measurements using ultrasound.

Table 2: Comparison between actual diameter of defects and measurements made using ultrasound.

\begin{tabular}{|c|c|c|c|}
\hline Area & $\begin{array}{c}\text { Mean difference } \\
\text { (True value-ultrasound) }\end{array}$ & $\begin{array}{c}\text { Standard Error } \\
\text { (True value-ultrasound) }\end{array}$ & P-value \\
\hline A & $\mathbf{0 . 0 5 9}$ & $\mathbf{0 . 0 5}$ & $\mathbf{0 . 2 4}$ \\
\hline LB & $-\mathbf{0 . 0 1 4}$ & 0.05 & 0.77 \\
\hline RB & $\mathbf{0 . 0 2 1}$ & $\mathbf{0 . 0 7}$ & $\mathbf{0 . 7 7}$ \\
\hline
\end{tabular}

Table 3 shows the comparison between ultrasound and conventional 2- D radiographs at different exposure time and angulation. The defects imaged were in the anterior and posterior mandible. At 12, 20 degrees, 18 and 8 impulses, the ANOVA shows statistically significant difference between measurements of defects using ultrasound and conventional radiographs. However at 12 impulses, 90 degrees and 10 degrees, no significance difference was detected. 
Table 3: Comparison between measurements of defects using ultrasound and 2-D radiographs at different exposure time and angulation.

\begin{tabular}{|c|c|c|c|c|}
\hline & Area & $\begin{array}{c}\text { Mean } \\
\text { difference } \\
\text { (ultrasound- } \\
\text { Conv) }\end{array}$ & $\begin{array}{c}\text { Standard } \\
\text { Error of the } \\
\text { Difference }\end{array}$ & P value \\
\hline 12 impulses & A & -0.012 & 0.05 & 0.80 \\
+90 degrees & LB & 0.035 & 0.02 & 0.10 \\
& RB & -0.09 & 0.18 & 0.61 \\
\hline 12 impulses & A & -0.040 & 0.056 & 0.47 \\
+10 degrees & LB & 0.035 & 0.030 & 0.26 \\
& RB & 0.058 & 0.058 & 0.32 \\
\hline 18 impulses & A & 0.061 & 0.11 & 0.03 \\
+ 90 degrees & LB & -0.151 & 0.03 & 0.00 \\
& RB & -0.186 & 0.03 & 0.00 \\
\hline 12 impulses & A & 0.087 & 0.09 & 0.37 \\
+20 degrees & LB & -0.219 & 0.05 & 0.00 \\
& RB & -0.303 & 0.04 & 0.00 \\
\hline 8 impulses, & A & 0.037 & 0.06 & 0.53 \\
\hline 90 degrees & LB & -0.386 & 0.14 & 0.01 \\
& RB & -0.185 & 0.04 & 0.00 \\
\hline
\end{tabular}

Tables 4-5 shows statistical results of comparison of ultrasound to actual defects based on defect size in anterior left buccal and right buccal.

Analysis of variance shows significant difference in left buccal area only. 
Table 4: Comparison of ultrasound based on defect size in anterior region

\begin{tabular}{|c|c|c|c|}
\hline Area A & Mean & Std Dev & $\begin{array}{c}\text { Analysis of } \\
\text { Variance }\end{array}$ \\
\hline $1 \mathrm{~mm}$ & 0.364 & 0.228 & \multirow{3}{*}{$\begin{array}{r}\text { Prob }>F \\
0.2260\end{array}$} \\
\hline $2 \mathrm{~mm}$ & 0.270 & 0.146 & \\
\hline $4 \mathrm{~mm}$ & 0.366 & 0.19 & \\
\hline
\end{tabular}

Table 5: Comparison of ultrasound based on defect size in the left buccal region

\begin{tabular}{|c|c|c|c|}
\hline Area LB & Mean & Std Dev & $\begin{array}{c}\text { Analysis of } \\
\text { Variance }\end{array}$ \\
\cline { 1 - 3 } $1 \mathrm{~mm}$ & 0.400 & 0.199 & \multirow{2}{*}{ Prob $>$ F } \\
0.005 \\
\cline { 1 - 2 }
\end{tabular}

Table 6: Comparison of ultrasound based on defect size in the right buccal region

\begin{tabular}{|c|c|c|c|}
\hline Area RB & Mean & Std Dev & $\begin{array}{c}\text { Analysis of } \\
\text { Variance }\end{array}$ \\
\cline { 1 - 3 } $1 \mathrm{~mm}$ & 0.396 & 0.235 & \multirow{2}{*}{$\begin{array}{c}\text { Prob }>\text { F } \\
0.149\end{array}$} \\
\hline $2 \mathrm{~mm}$ & 0.278 & 0.251 & 0.352 \\
\hline $4 \mathrm{~mm}$ & 0.485 & 0.45 \\
\hline
\end{tabular}


Table 7 shows statistical significance in area LB at the size of $2 \mathrm{~mm}$ defect

Table 7: Comparison of ultrasound to actual defects based on defect size using Tukey- Kramer

\begin{tabular}{|c|c|c|c|}
\hline Defect size & Area A & Area LB & Area RB \\
\hline $1 \mathbf{m m}$ & A & A & A \\
\hline $2 \mathbf{m m}$ & A & B & A \\
\hline $4 \mathbf{m m}$ & A & A & A \\
\hline
\end{tabular}

Levels not connected by same letter are significantly different

Tables 8-10 show statistical results of comparison of conventional radiographs to actual defects based on defect size in anterior left buccal and right buccal.

Table 8: Comparison of conventional based on defect size in anterior region

\begin{tabular}{|c|c|c|c|}
\hline Area A & Mean & Std Dev & $\begin{array}{c}\text { Analysis of } \\
\text { Variance }\end{array}$ \\
\cline { 1 - 3 } $1 \mathrm{~mm}$ & 0.642 & 0.248 & \multirow{2}{*}{$\begin{array}{c}\text { Prob }>\text { F } \\
0.0001\end{array}$} \\
\cline { 1 - 3 } $2 \mathrm{~mm}$ & 0.329 & 0.457 & \\
\cline { 1 - 3 } & 0.152 & 0.146 & \\
\hline
\end{tabular}

Table 9: Comparison of conventional based on defect size in left buccal region

\begin{tabular}{|c|c|c|c|}
\hline Area A & Mean & Std Dev & $\begin{array}{c}\text { Analysis of } \\
\text { Variance }\end{array}$ \\
\cline { 1 - 3 } $1 \mathrm{~mm}$ & 0.468 & 0.228 & \multirow{2}{*}{$\begin{array}{c}\text { Prob }>\text { F } \\
\text { 2mm }\end{array}$} \\
\cline { 1 - 3 } & 0.113 & 0.146 & \\
\hline $4 \mathrm{~mm}$ & 0.366 & 0.19 & \\
\hline
\end{tabular}


Table 10: Comparison of conventional based on defect size in right buccal region

\begin{tabular}{|c|c|c|c|}
\hline Area A & Mean & Std Dev & $\begin{array}{c}\text { Analysis of } \\
\text { Variance }\end{array}$ \\
\cline { 1 - 3 } $1 \mathrm{~mm}$ & 0.630 & 0.248 & \multirow{2}{*}{$\begin{array}{c}\text { Prob }>\text { F } \\
0.0001\end{array}$} \\
\cline { 1 - 3 } $2 \mathrm{~mm}$ & 0.206 & 0.184 & \\
\cline { 1 - 3 } & 0.150 & 0.127 & \\
\hline
\end{tabular}

Table 11 shows statistical significance in all areas at the size of $1 \mathrm{~mm}$ defect

Table 11: Comparison of conventional to actual defects based on defect size using TukeyKramer

\begin{tabular}{|c|c|c|c|}
\hline Defect size & Area A & Area LB & Area RB \\
\hline $1 \mathbf{m m}$ & A & A & A \\
\hline $2 \mathbf{m m}$ & B & B & B \\
\hline $4 \mathbf{m m}$ & B & B & B \\
\hline
\end{tabular}

Levels not connected by same letter are significantly different

\section{Survey Results}

\section{Comparison of Ultrasound and Conventional Radiographs:}

Figure 1 shows the number of times the evaluators who preferred either the 2-D conventional radiograph or the Ultrasound in image quality. The evaluators felt that 16 out of 30 ultrasound images were good quality, 13 were fair and 1 was poor. For the 2-D radiographs, the evaluators ranked 13 radiographic images as good, 11 as fair and 6 as poor quality image. From figure1, ultrasound images were mostly in the good and fair category. 
Figure 1: Comparison of quality of image between ultrasound and radiographs

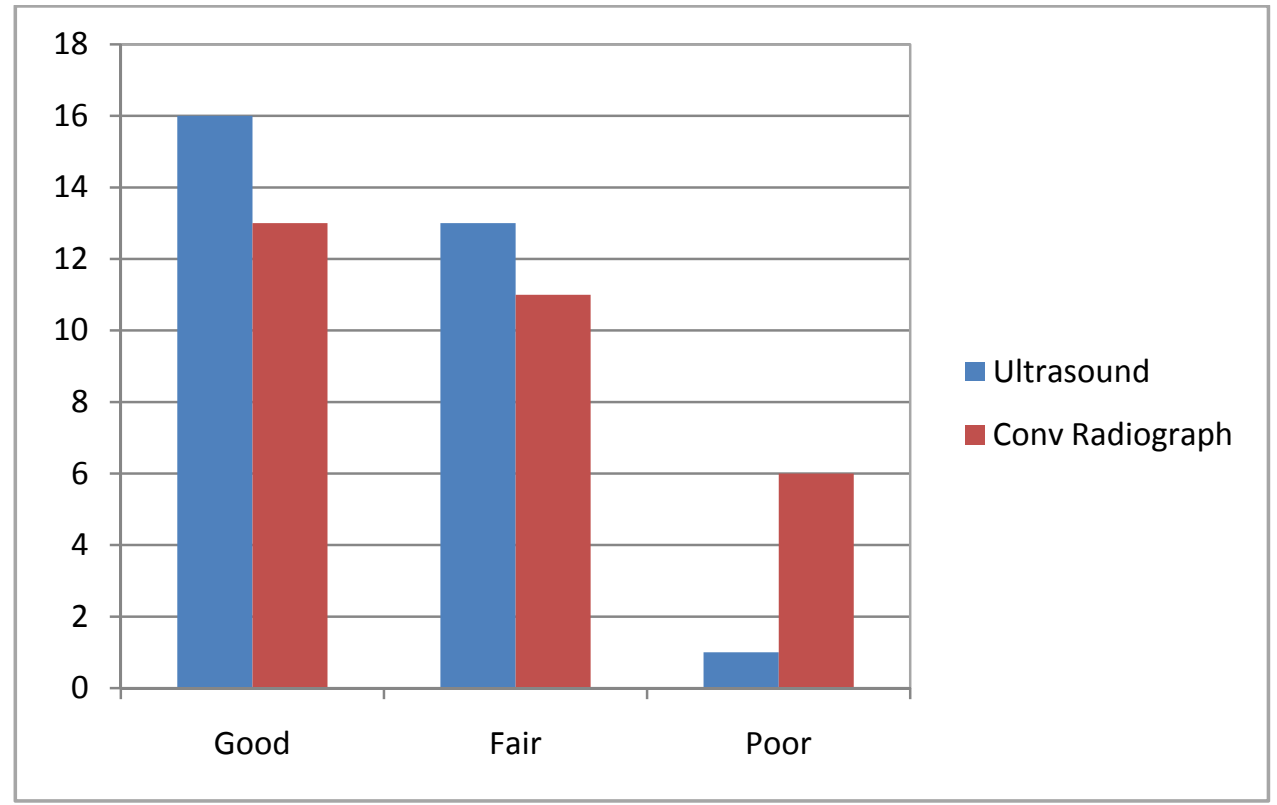

In reporting fatigue level, 16 images had low fatigue level, 14 medium and zero ultrasound images had high fatigue level. While 14 of the conventional 2-D radiograph images had low fatigue, 14 medium and 2 of the x-ray images had high fatigue level More ultrasound images were associated with low to medium fatigue than radiographs (Figure 2). 
Figure 2: Comparison of fatigue level between ultrasound and radiographs

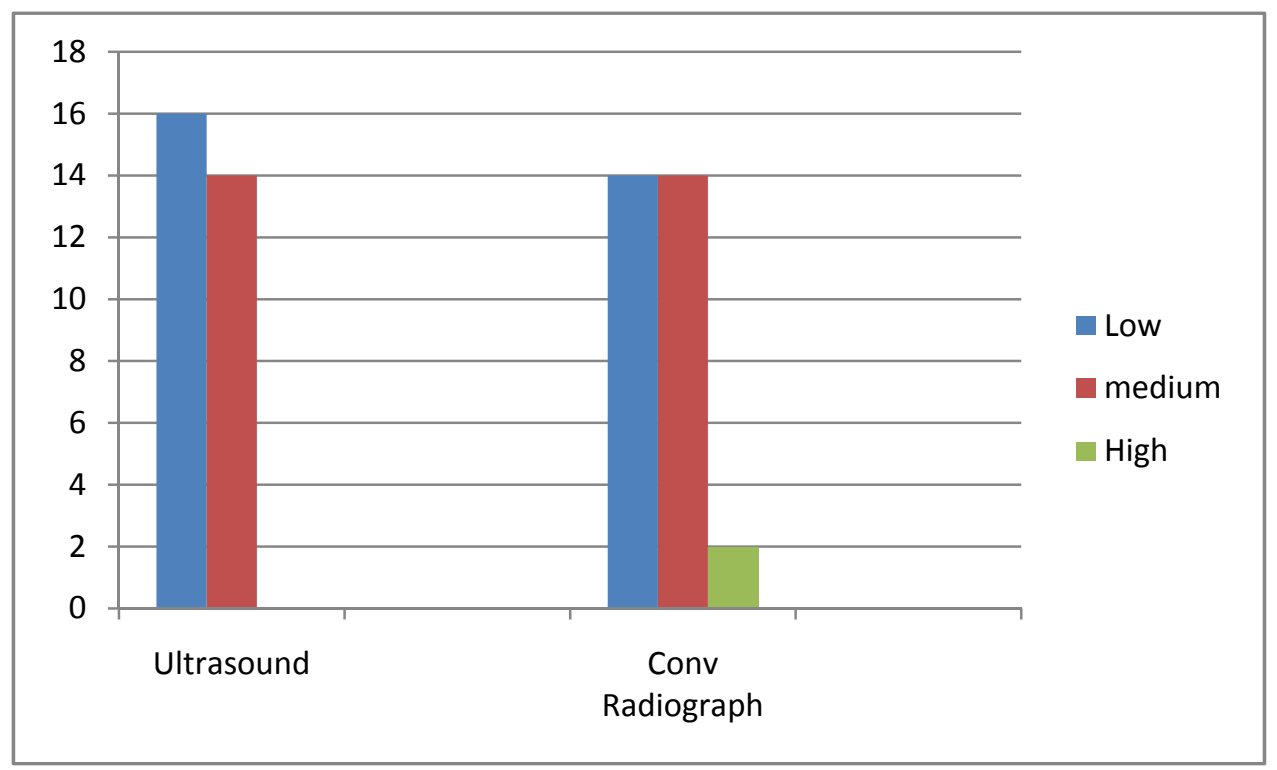

Figure 3 shows the percentage of evaluators who preferred either the ultrasound or 2-D conventional radiograph based on image clarity. The conventional 2-D x-ray was preferred in 14 out of the 30 images. Ultrasound images were preferred 13 times out of 30 . Three images showed identical preference from the evaluators. Radiographs were preferred more by the panel. However, ultrasound images were found to have more details. The statistical differences were not calculated due to the small sample size. However, the contingency analysis reveals -0.27 Kappa value indicating, a poor agreement among the evaluations. 
Figure 3: Image preferences between ultrasound and radiographs

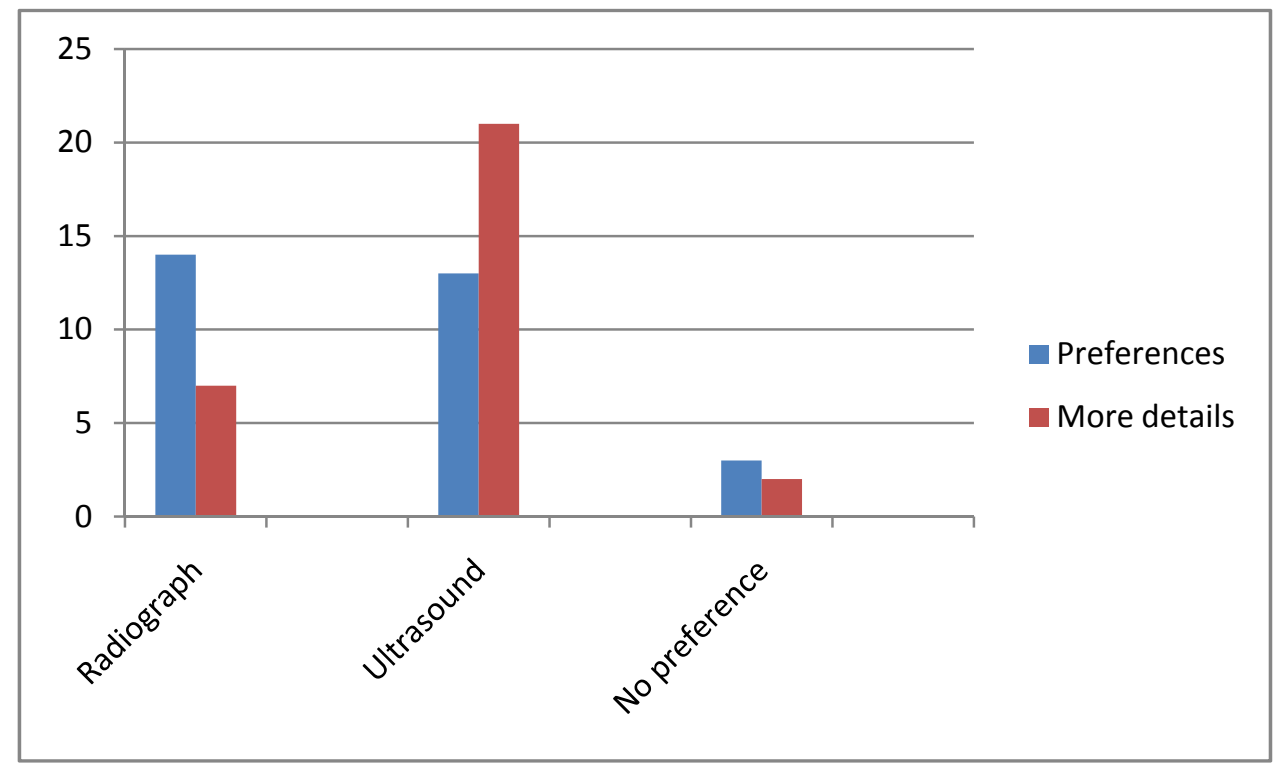

\section{The Dentate Mandible with Natural Periodontal Defect}

\section{Comparison of Ultrasound and Cone Beam:}

Figure 4 show that 5 out of 6 ultrasound images were considered good quality. While 3 out of 6 of cone beam images were considered good, it seems that the ultrasound image quality were perceived as good quality more often than the cone beam 
Figure 4: Comparison of quality of image between ultrasound and cone beam.

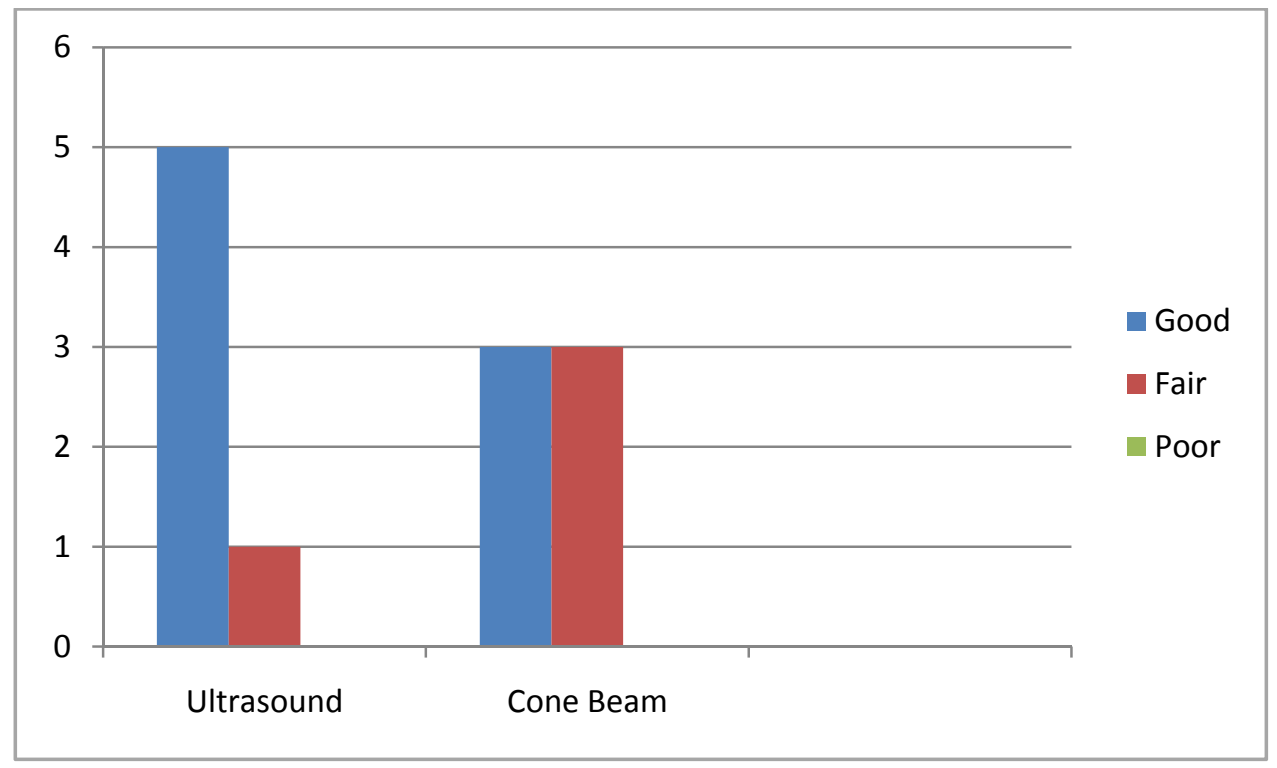

In reporting fatigue level, 16 images had low fatigue level, 4 out of 6 ultrasound images had low fatigue reported while 3 out of 6 radiographs had low fatigue

More ultrasound images were associated with low fatigue than radiographs

Figure 5: Comparison of Fatigue level between ultrasound and radiographs

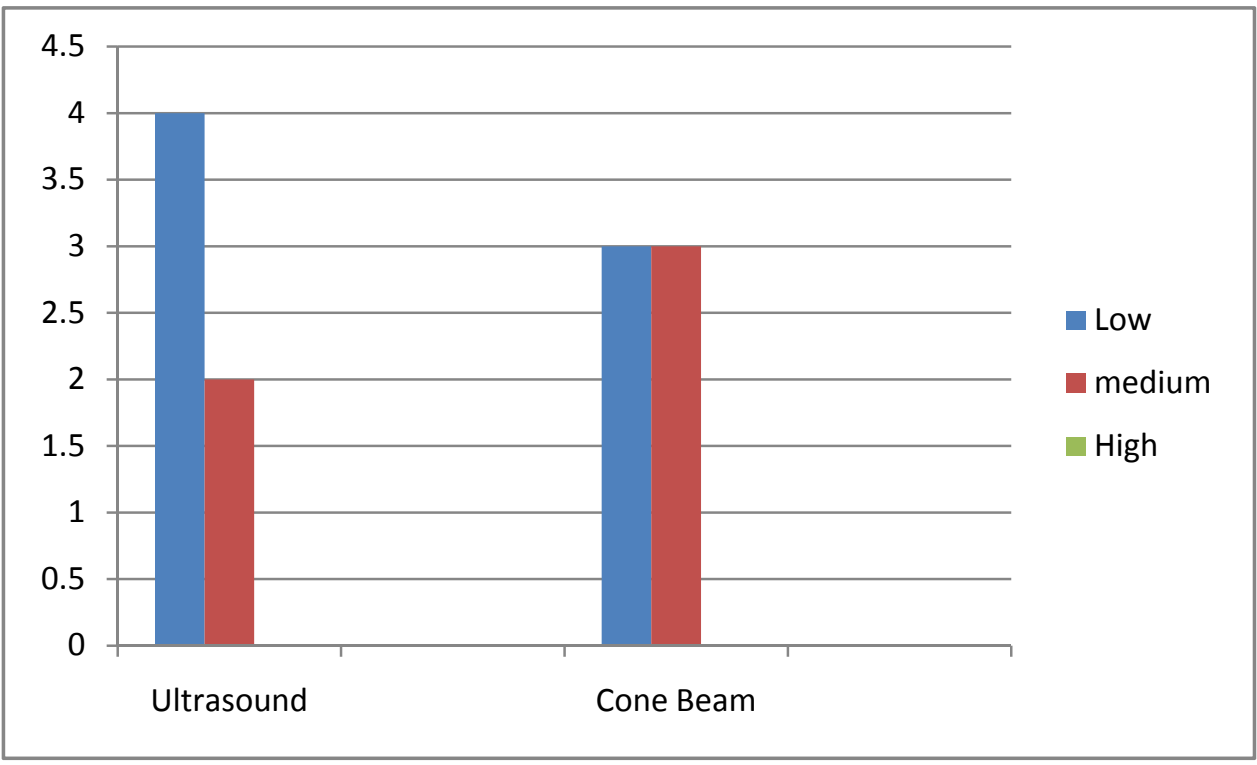


Figure 6 shows that the panel of 3 evaluators preferred the ultrasound images. Furthermore, the panel also preferred the ultrasound on the basis of image detail.

Figure 6: Image preferences between ultrasound and cone beam

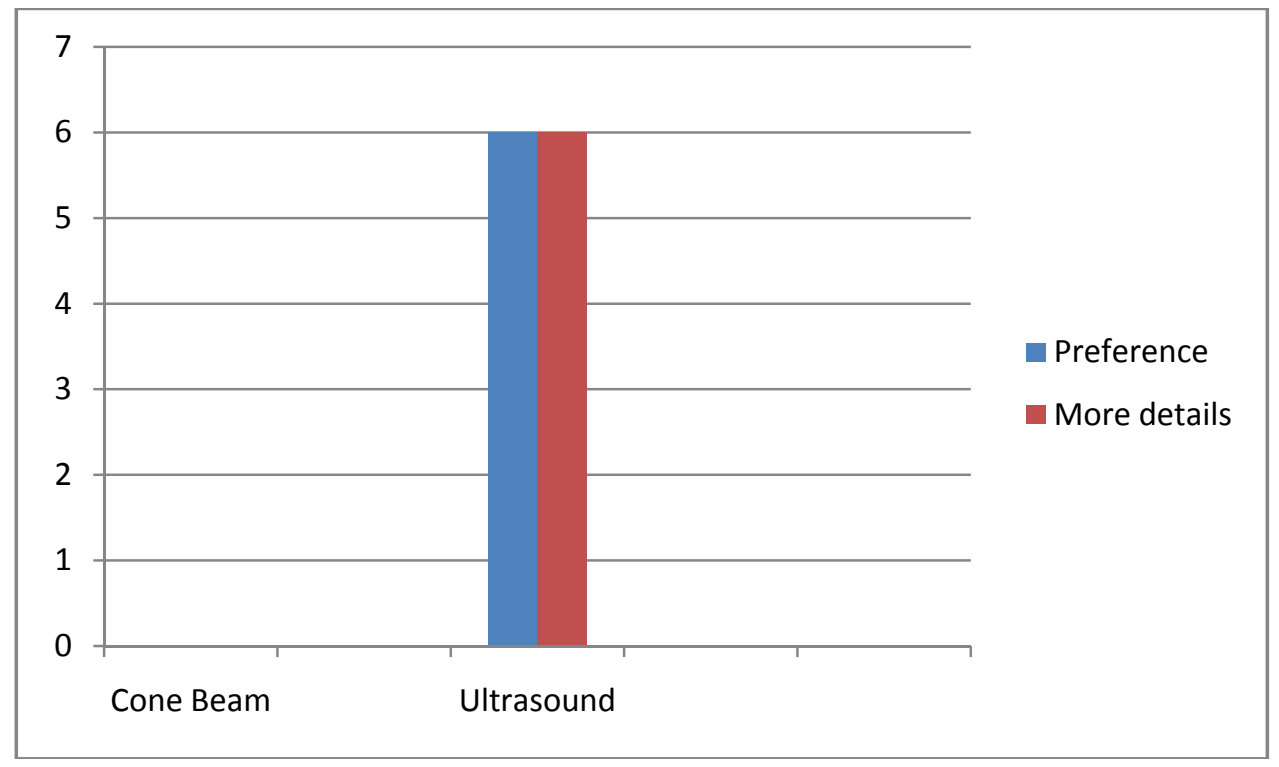




\section{DISCUSSION}

\section{The Edentulous Mandibles with Simulated Periodontal Defects}

Irrespective of the x-ray beam variables used: 12 impulses, 90 degrees; 12 impulses, +10 degrees; 12 impulses, +20 degrees; 8 impulses, 90 degrees; or 18 impulses, 90 degrees, no significant differences were found between conventional 2-D radiographs and the actual defects in the anterior region.

Irrespective of the x-ray beam variables used: 12 impulses, 90 degrees; 12 impulses, +10 degrees; 12 impulses, +20 degrees; 8 impulses, 90 degrees; or 18 impulses, 90 degrees, significant differences were found between conventional radiographs and the actual defects in the right and left buccal posterior region of the mandible. Morris et al. ${ }^{32}$ found that the majority of the posterior mandible was composed of Q-2 bone, which was a large, dense layer of cortical bone surrounding a dense trabecular core. Misch et al. ${ }^{33}$ found that the posterior mandible is mostly composed of fine trabecular bone with a thinner cortical plate. An explanation may be that the lesser density of the posterior bone rendered a darker radiographic image with lesser contrast between the defect and the adjacent bone and thus resulting in less accurate measurements. Also, the effect of drilling the simulated defects intracortically into more delicate trabecular bone may have been traumatic to the dried mandibles. This brittle bone may have fractured more than was expected reducing the overall density differences that should have existed.

No significant differences were found between ultrasound measurements and actual defects for left buccal regions only. This shows that ultrasound is reliable in imaging bone defects. This is in agreement with Lost et al. ${ }^{29}$ who concluded that ultrasound could provide 
reliable images of the alveolar crest and the gingival tissues and sometimes of the entrance of the periodontal ligament space.

Irrespective of the area imaged, at 12 impulses, 90 degrees and 12 impulses, 10 degrees, no significant differences were found between ultrasound and conventional 2-D radiographs. Thus, no difference seems apparent between imaging performed in D2 bone of the anterior mandible and D3 of the posterior mandible. However, at 12 impulses, 20 degrees, 18 impulses, 90 degrees, 8 impulses, 90 degrees, ANOVA found these differences to be significant in the posterior region. An explanation of this result would be what previously discussed about the difference in bone quality between anterior and posterior mandible. Even though there was significant differences between ultrasound and 2-D radiographs in most of the measurements, there wasn’t enough statistical difference at 12 impulses, 90 degrees and 12 impulses, 10 degrees, Thus, the null hypothesis of no significant difference exists between ultrasound images and conventional 2-D radiographs of higher density/quality anterior mandibular bone and lower density/quality posterior mandibular bone cannot be rejected. However, a trend of better imaging with ultrasound was seen and more research in the future may confirm this observation.

At 12 impulses, 10 degrees, the one way analysis test found that the conventional 2-D radiograph showed statistically significant differences in determining simulated defect diameter based on the defect size in the anterior region. Furthermore, comparison using the Tukey-Kramer test reveals that the measurement of the $1 \mathrm{~mm}$ defect size is significantly different. A small defect size of $1 \mathrm{~mm}$ in a dense cortical bone of the anterior mandible may be hard to discern using traditional periapical radiographs.

No significant differences were found between the ultrasound measurements and actual defects for the anterior and posterior regions. Based on the defect size, ANOVA reveals 
significant difference only in left buccal area. This may be explained with the ultrasound positional errors. It is possible that access to the submerged mandible from the left side was compromised. Comparisons using Tukey-Kramer test showed significant difference in measuring the 2mm defect. Furthermore, no statistical difference was noted in either method's ability to more accurately distinguish between the large $4 \mathrm{~mm}$ defect. Therefore, if the defect was present the ultrasound was just as successful as 2-D conventional radiograph in imaging the defect's diameter. This result is in agreement with. Tsiolis and Needleman ${ }^{5}$ who, in their study to investigate high frequency ultrasound imaging for periodontal probing, concluded that ultrasonography provides a highly accurate and repeatable technique for periodontal assessment. In contrary Palou et al concluded that measurements of the alveolar bone topography with their ultrasonic probe were not accurate and there were problems with reproducibility. ${ }^{34}$ Spranger who tried to determine the height of alveolar crest in periodontitis patients concluded that if carefully used this technique could add some information to X-ray diagnosis. ${ }^{6}$ In light of the results of this study, ultrasonography is a promising imaging technology in the field of dentistry.

\section{Survey Phase}

In terms of image quality, the panel of 3 evaluators preferred the ultrasound images. Furthermore, the panel also preferred the ultrasound on the basis of image detail. while statistical significance was not calculated due to the small number of evaluators, one can still draw the conclusion that the panel felt the ultrasound images were an improvement in quality and detail over the conventional radiographs. Although, the evaluators are more familiar and experienced at reading radiographs, they reported less fatigue level with ultrasound images. Ultrasound images are one to one and the images exhibit more depth and better resolution. 


\section{The Dentate Mandible with Natural Periodontal Defect}

In terms of image quality, and in comparing cone beam images to ultrasound images, the panel of 3 evaluators preferred the ultrasound images. Furthermore, the panel also preferred the ultrasound on the basis of image detail. Again, statistical significance was not performed due to the small number of evaluators. However the panel felt the ultrasound images were an improvement in quality and detail over the buccal image of the cone beam. In reality, the cone beam images can be seen from different angles, providing more detailed information. In this study and for the sake of comparisons, only the buccal image was compared to the ultrasound. The two imaging modalities are very different, thus comparison is challenging. 


\section{CHAPTER V}

\section{SUMMARY}

The purpose of this study is to investigate the efficacy of ultrasound imaging to accurately detect periodontal defects. The first phase of the study involved the placement of simulated periodontal defects of specific dimension into the edentulous dried human cadaver mandibles. These simulated defects were then radiographed and the effect of variation in exposure time and beam angulation on the defect detection was also evaluated. First, x-ray beam angulation was kept constant at $90^{\circ}$, and exposure time was varied between 8, 12, and 18 impulses. Next, exposure time was kept constant at 12 impulses, and beam angulation was varied between $90^{\circ}$ (perpendicular) and $10^{\circ}$ and $20^{\circ}$ to the perpendicular in the horizontal plane. The same simulated defects were then imaged using ultrasound. The scanned images with adequate quality and clarity were captured. The ultrasound and the conventional radiographs were then evaluated. The defects diameters on each ultrasound image and radiograph were measured. The ability of the ultrasound to accurately image the defect was compared to that of the actual defects and the conventional radiograph. The Second phase of this study compared the ultrasound images to 2-D radiographs of simulated defect in basis of image quality, fatigue level and amount of details. Moreover, 3-D ultrasound images were compared to 3-D cone beam images of natural periodontal defects. A panel of three evaluators consisting of two periodontists and one orthodontist were asked to evaluate both the 2-D and 3-D images. First they were shown a randomized compilation of 10 images of simulated defects. These images consisted of ultrasound and their conventional radiographs. The panel was asked to evaluate the quality, clarity, and detail, as well as their perceived level of fatigue in looking at the images of both the ultrasound and conventional 2-D radiographs. Then they were asked to compare reconstructed 3-D 
ultrasound images of two mandibles with natural periodontal defects to cone beam images. The panel of three professional evaluators was presented with these 3-D ultrasound reconstructed images to compare to cone beam images of the same periodontal defects.

The results have shown that conventional radiographs were not accurate in imaging the posterior mandible, while measurements made from ultrasound images were accurate for both anterior and posterior mandibles. The bone quality difference between the anterior and posterior mandible did not affect the accuracy of ultrasound imaging. The ultrasound images were also rated favorably in image clarity, image detail, overall image quality, and fatigue levels. Surveyed clinicians preferred the traditional radiographs since they are more familiar with reading $\mathrm{x}$-rays. It is possible that these clinicians may favor the ultrasound once they are more familiar with reading them. The panel also felt the ultrasound images were an improvement in quality and detail over the buccal image of the cone beam. In reality, the cone beam images can be seen from different angles, providing more detailed information. In this study and for the sake of comparisons, only the buccal image was compared to the ultrasound. The two imaging modalities are very different, thus comparison is challenging.

\section{Conclusions}

The following conclusions were made.

1. No significant difference exists between accuracy of measurements obtained from ultrasound images and conventional 2-D radiographs when the width of defect was varied. 
2. No significant difference exists between accuracy of measurements obtained from ultrasound images and conventional 2-D radiographs when the exposure time was varied.

3. No significant difference exists between accuracy of measurements obtained from ultrasound images and conventional 2-D radiographs when the beam angulation was varied.

4. Significant difference exists between accuracy of measurements obtained from ultrasound images and 2-D radiographs when bone density (anterior and posterior part of the mandible) was varied.

\section{Comparison of ultrasound and conventional radiographs using natural periodontal defects}

1. No significant difference exists in the levels of image clarity, image detail, overall image quality, and fatigue levels between 2-D ultrasound images and conventional 2-D radiographs.

\section{Comparison of ultrasound and conventional radiographs using natural periodontal defects}

1. No significant difference exists in the levels of image clarity, image detail, overall image quality, and fatigue levels between 3-D ultrasound images and 3-D Cone beam images. 


\section{Recommendations}

Upon completion of this study, the following recommendations were made:

1. Sample size in the survey should be increased for further evaluation of the dental practitioner's preference for the ultrasound images.

2. Repeat this study using a large sample of natural periodontal defects.

3. Reconstructed 3-D ultrasound images are quite different. Improvement in reconstructing these images will encourage the use of this type of imaging

4. Increase familiarity with ultrasound imaging in dentistry.

5. Develop small ultrasound probes that can be used in the oral cavity.

6. Develop software that will do automatic interpretation to ultrasound images. This may overcome resistance from dental clinicians to use this new modality. 


\section{Reference List}

(1) Eickholz P, Kim TS, Benn DK, Staehle HJ. Validity of radiographic measurement of interproximal bone loss. Oral Surg Oral Med Oral Pathol Oral Radiol Endod 1998 January;85(1):99-106.

(2) Seabra RC, Costa FO, Costa JE, Van DT, Soares RV. Impact of clinical experience on the accuracy of probing depth measurements. Quintessence Int 2008 July;39(7):559-65.

(3) Jeffcoat MK, Wang IC, Reddy MS. Radiographic diagnosis in periodontics. Periodontol 20001995 February;7:54-68.

(4) BAUM G, GREENWOOD I, SLAWSKI S, SMIRNOW R. Observation of internal structures of teeth by ultrasonography. Science 1963 February 8;139:495-6.

(5) Tsiolis FI, Needleman IG, Griffiths GS. Periodontal ultrasonography. J Clin Periodontol 2003 October;30(10):849-54.

(6) Spranger H. Ultra-sonic diagnosis of marginal periodontal diseases. Int Dent J 1971 December 4;21(4):442-55.

(7) Carranza FA NM. Clinical Periodontology. 8 ed. 2009.

(8) Theilage J. An evaluation of the reliability of radiographs in the measurement of bone loss in periodontal disease. J Periodontol 1996;31:143-53.

(9) Cirelli CC, Cirelli JA, da Rosa Martins JC, Lia RC, Rossa C, Jr., Marcantonio E Jr. Orthodontic movement of teeth with intraosseous defects: Histologic and histometric study in dogs. Am J Orthod Dentofacial Orthop 2003 June;123(6):666-73.

(10) Cortellini P, Pini PG, Tonetti MS. Periodontal regeneration of human infrabony defects. II. Re-entry procedures and bone measures. J Periodontol 1993 April;64(4):261-8.

(11) Kessler M. Interrelationships between orthodontics and periodontics. Am J Orthod 1976 August;70(2):154-72.

(12) Polson A, Caton J, Polson AP, Nyman S, Novak J, Reed B. Periodontal response after tooth movement into intrabony defects. J Periodontol 1984 April;55(4):197-202.

(13) Brown IS. The effect of orthodontic therapy on certain types of periodontal defects. I. Clinical findings. J Periodontol 1973 December;44(12):742-56.

(14) Kazandjian G, Scopp IW, Stahl S. Combined orthodontic-periodontal treatment of an infrabony defect. A case report. J Periodontol 1979 September;50(9):479-82.

(15) Vanarsdall RL Jr GT. Orthodontics current principles and thechniques. 2 ed. st louis: 1994. 
(16) Ericsson I, Thilander B, Lindhe J, Okamoto H. The effect of orthodontic tilting movements on the periodontal tissues of infected and non-infected dentitions in dogs. J Clin Periodontol 1977 November;4(4):278-93.

(17) Geraci TF, Nevins M, Crossetti HW, Drizen K, Ruben MP. Reattachment of the periodontium after tooth movement into an osseous defect in a monkey. 1. Int J Periodontics Restorative Dent 1990;10(3):184-97.

(18) Proffit WR FH. Contemporary orthodontics. Mosby; 2000.

(19) Mathews DP, Kokich VG. Managing treatment for the orthodontic patient with periodontal problems. Semin Orthod 1997 March;3(1):21-38.

(20) Papapanou PN, Wennstrom JL. The angular bony defect as indicator of further alveolar bone loss. J Clin Periodontol 1991 May;18(5):317-22.

(21) Suomi JD, Plumbo J, Barbano JP. A comparative study of radiographs and pocket measurements in periodontal disease evaluation. J Periodontol 1968 November;39(6):3115 .

(22) Pepelassi EA, Tsiklakis K, amanti-Kipioti A. Radiographic detection and assessment of the periodontal endosseous defects. J Clin Periodontol 2000 April;27(4):224-30.

(23) Tonetti MS, Pini PG, Williams RC, Cortellini P. Periodontal regeneration of human infrabony defects. III. Diagnostic strategies to detect bone gain. J Periodontol 1993 April;64(4):269-77.

(24) Lang NP, Hill RW. Radiographs in periodontics. J Clin Periodontol 1977 February;4(1):16-28.

(25) Stoner JE. An investigation into the accuracy of measurements made on radiographs of the alveolar crests of dried mandibles. J Periodontol 1972 November;43(11):699-701.

(26) Hagen-Ansert. Diagnostic ultrasonography. 6 ed. Mosby; 2006.

(27) Ghorayeb SR, Maione E, La M, V. Modeling of ultrasonic wave propagation in teeth using PSpice: a comparison with finite element models. IEEE Trans Ultrason Ferroelectr Freq Control 2001 July;48(4):1124-31.

(28) Ursell MJ. Relationships between alveolar bone levels measured at surgery, estimated by transgingival probing and clinical attachment level measurements. J Clin Periodontol 1989 February;16(2):81-6.

(29) Lost C, Irion KM, Nussle W. Ultrasonic B-scans of the facial/oral periodontium in pigs. $J$ Clin Periodontol 1989 September;16(8):534-8. 
(30) Hazey MA, III, Ngan P, Reed H, Razmus T, Crout R, Kao E. Comparison of computergenerated, enhanced and conventional 2-dimensional radiographic imaging. Am J Orthod Dentofacial Orthop 2009 April;135(4):463-7.

(31) Mahmoud A, Cortes D, Abaza A et al. Noninvasive assessment of human jawbone using ultrasonic guided waves. IEEE Trans Ultrason Ferroelectr Freq Control 2008;55(6):131627.

(32) Truhlar RS, Orenstein IH, Morris HF, Ochi S. Distribution of bone quality in patients receiving endosseous dental implants. J Oral Maxillofac Surg 1997 December;55(12 Suppl 5):38-45.

(33) Misch CE, Qu Z, Bidez MW. Mechanical properties of trabecular bone in the human mandible: implications for dental implant treatment planning and surgical placement. $J$ Oral Maxillofac Surg 1999 June;57(6):700-6.

(34) Palou ME, McQuade MJ, Rossmann JA. The use of ultrasound for the determination of periodontal bone morphology. J Periodontol 1987 April;58(4):262-5. 


\section{APPENDIX A}

Survey 
Dear Doctors,

Thank you for taking the time to participate in my research,. This part of study intends to compare the ultrasound image to the traditional radiographic image of defects placed in the body of ten 10 different mandibles. The images are presented as obtained by the two imaging systems.

Directions:

Please download the attached word file which contains the answer sheet.

Please open the PowerPoint presentation, to view the mandibles while placing your answer on the answer sheet.

Please fill in the questionnaire presented in the table for each labeled mandible.

Please either email me the answer sheet or let me know when to pick up the hard copy.

Sincerely

Rajia Sebbahi D.M.D

3rd year orthodontic resident

WVU Department of Orthodontics 


\section{Survey Sample}

Interviewer:

Mandible \#:

\begin{tabular}{|c|c|c|c|}
\hline Image & Image Quality & $\begin{array}{l}\text { Confidence level of exam(how } \\
\text { sure are you) }\end{array}$ & $\begin{array}{l}\text { Fatigue level viewing image(low or high } \\
\text { strain in discerning the image) }\end{array}$ \\
\hline Ultrasound & $\begin{array}{l}\text { Good } \\
\text { Fair } \\
\text { Poor }\end{array}$ & 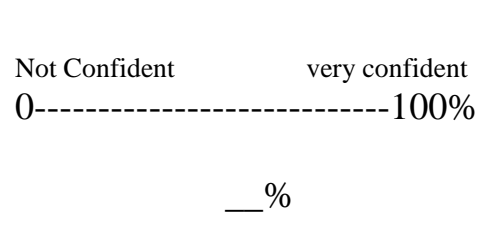 & ${ }_{1-2-3-4-5}^{\text {High }}$ \\
\hline Radiograph & $\begin{array}{l}\text { Good } \\
\text { Fair } \\
\text { Poor }\end{array}$ & $\begin{array}{l}\text { Not Confident } \quad \text { very confident } \\
\text { 0---100\% } \\
\text { — \% }\end{array}$ & Low $1-2-3-4-5$ High \\
\hline
\end{tabular}

\begin{tabular}{|c|c|c|}
\hline $\begin{array}{l}\text {-Is there improved } \\
\text { image clarity between } \\
\text { the images? }\end{array}$ & $\begin{array}{l}\text {-Are you able to } \\
\text { discern more } \\
\text { details from one } \\
\text { image? }\end{array}$ & Personal observations or comments: \\
\hline & Yes No & \\
\hline -If so which is better? & & \\
\hline -Ultrasound & $\begin{array}{l}\text {-Which image } \\
\text { has more detail? }\end{array}$ & \\
\hline -Radiograph & -Ultrasound & \\
\hline $\begin{array}{l}\text {-How much } \\
\text { improvement? } \\
\text { Small improvement } \\
\text { Large improvement }\end{array}$ & -Radiograph & \\
\hline
\end{tabular}




\section{Survey Sample}
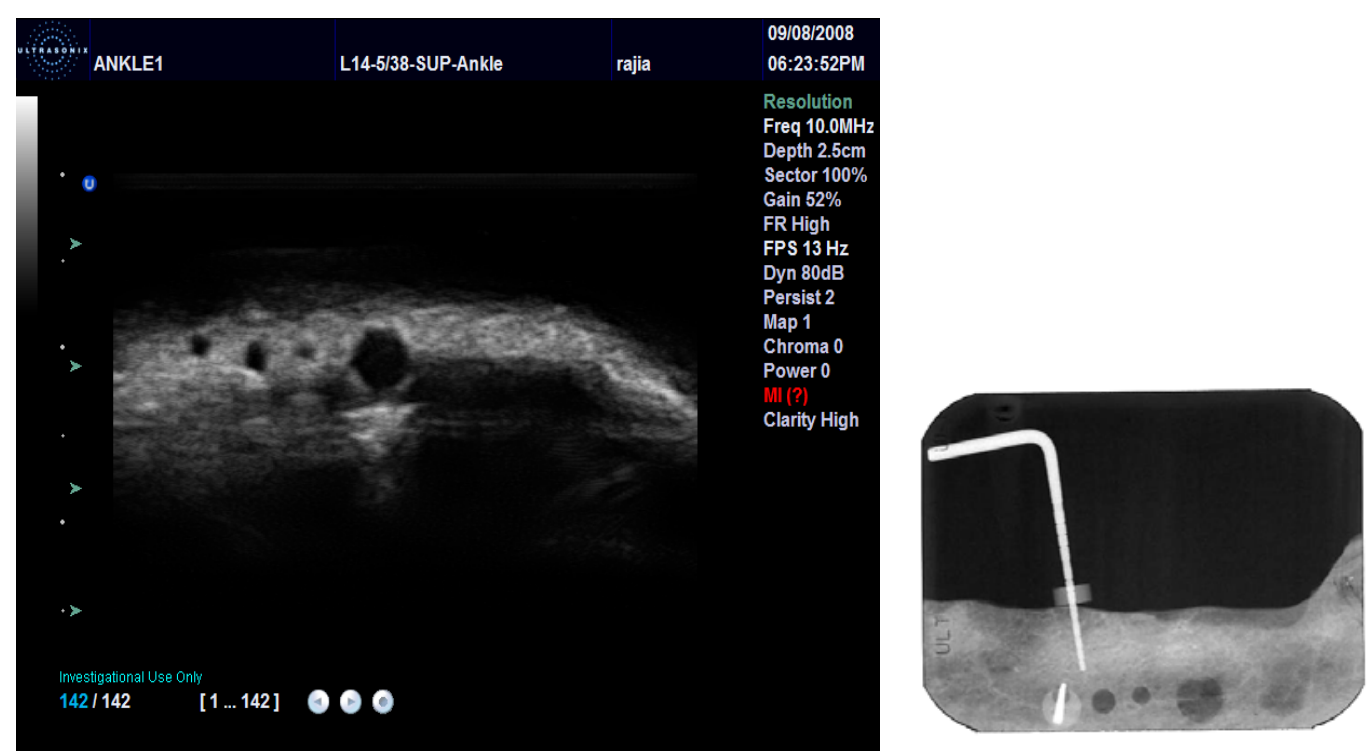


\section{APPENDIX B}

Orientation PowerPoint presentation to familiarize the evaluators with 3-D reconstructed images. 


\section{Dear Doctors,}

Thank you for taking the time to participate in my research,. This part of the study intends to compare the 3-D ultrasound images to the cone beam images. Please evaluate the images of the two mandibles with reference to the periodontal defects.

I have oriented the cone beam image so we can objectively compare to the ultrasound image.

Directions to evaluate the images:

Please download the attached word file which contains the answer sheet.

Please open the orientation Power Point presentation

Please open the PowerPoint presentation, to view the mandibles while putting your answer on the answer sheet.

Please fill in the questionnaire presented in the table for each labeled mandible.

Please either email me the answer sheet or let me know when to pick up the hard copy. Thank you.

Sincerely

Rajia Sebbahi, D.M.D,

3rd year orthodontic resident

WVU Department of Orthodontics 
The following orientation slides introduce the evaluators to 3-D reconstructed ultrasound image. The ultrasound image is superimposed on the mandible to help orient the reader. Landmarks have been labeled to familiarize the reader with $3 \mathrm{D}$ ultrasound image. The color indicates depth with the red as most shallow and blue the deepest. 


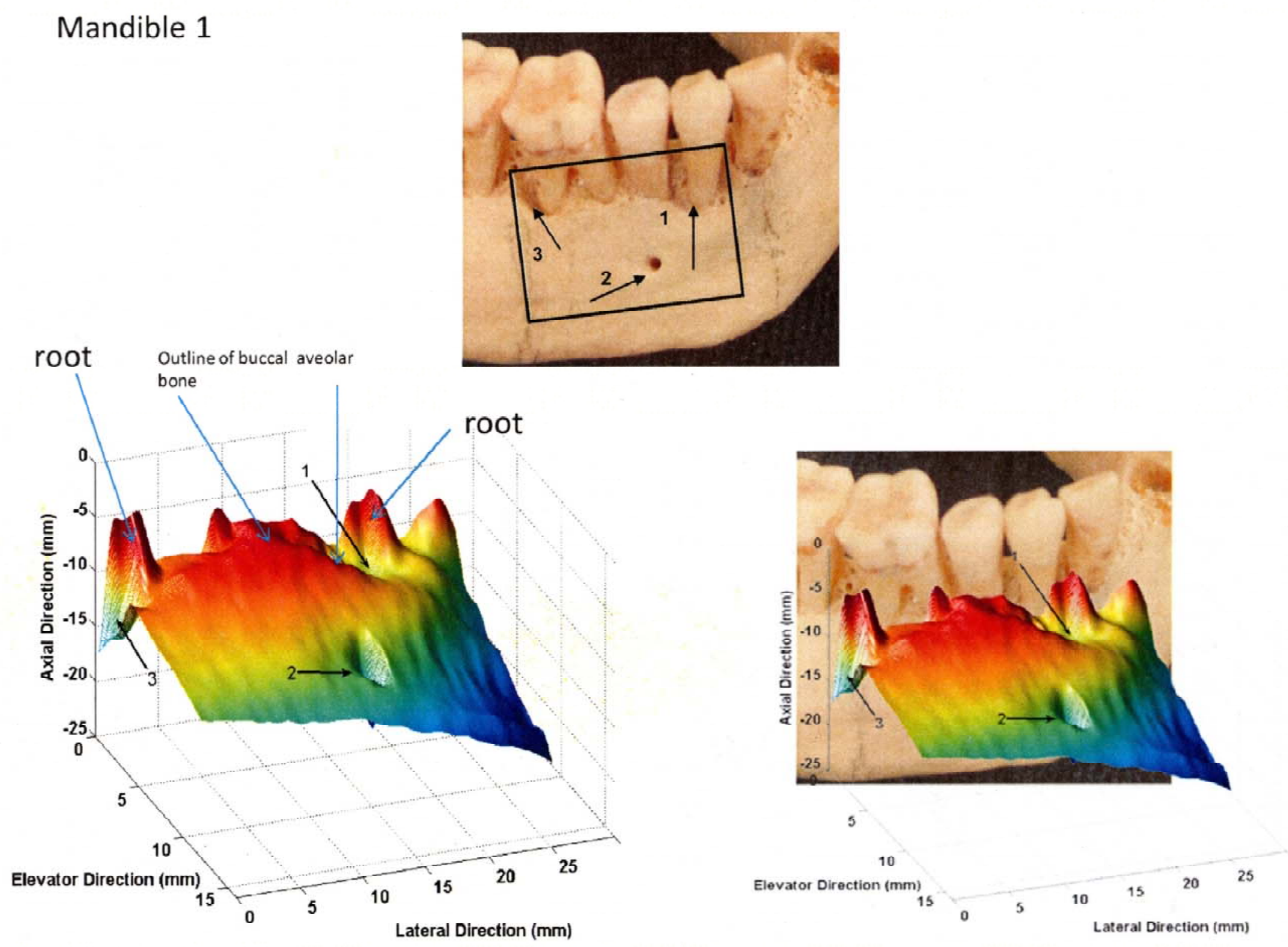




\section{Mandible 2}
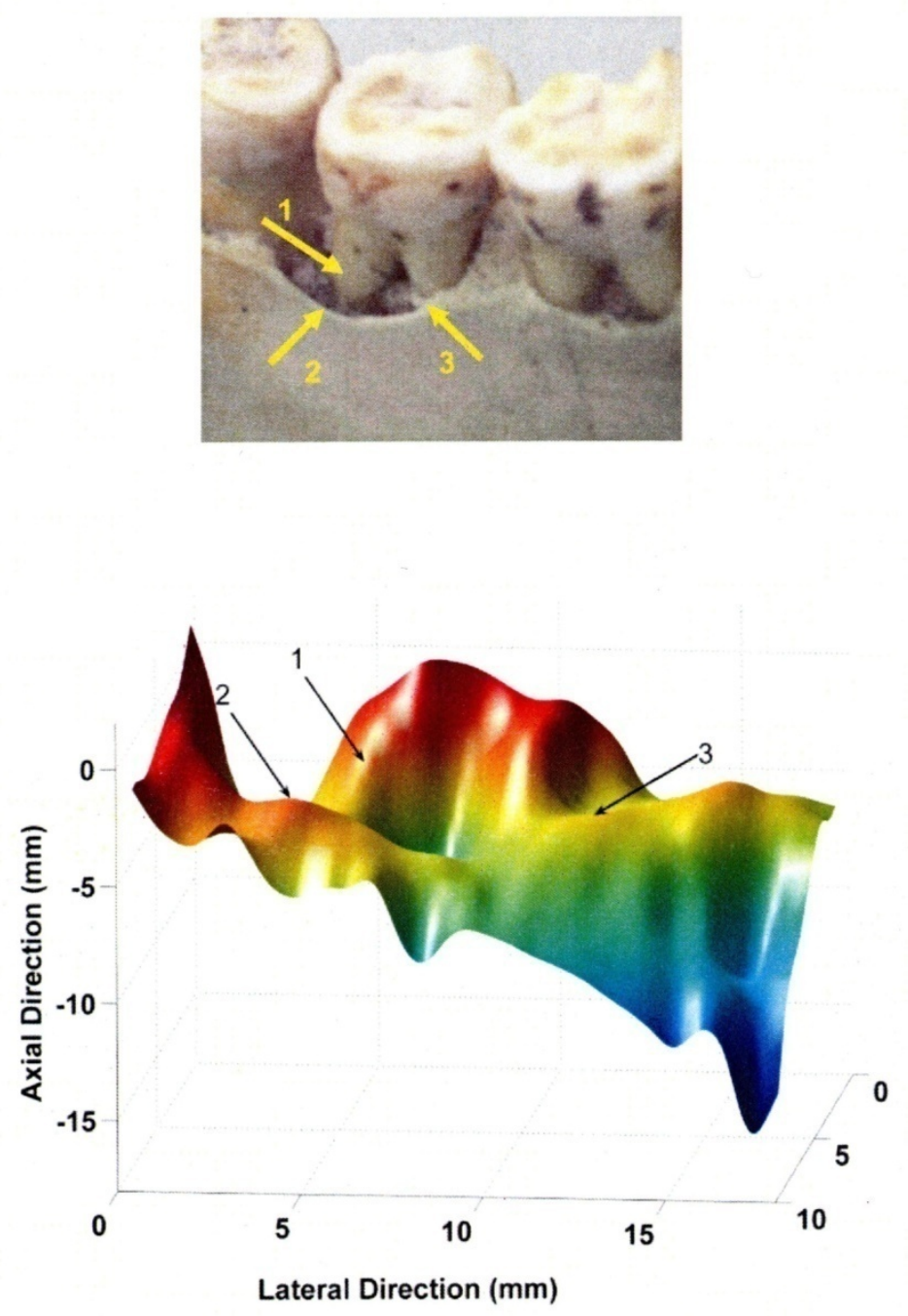


\section{Rajia Sebbahi}

Education

2001-2005 Tufts University School of Dental Medicine Boston, MA Doctor of Dental Medicine, Summa Cum Laude

1999-2000 Southern Arkansas University Magnolia, Arkansas Majored in Biology/ Pre-Dental.

Cumulative GPA of 3.96 (4.0 scale)

1995-1997 Texas A\&M University - Kingsville, Texas

Received a Bachelor of Business Administration, Cumulative GPA of 3.92 (4.00 scale)

1993-1995 International Institute of Higher Education (IIHE) Morocco Majored in Information System Cumulative GPA 3.85 (4.00 scale)

Honors \& Awards

- Inducted into Omicron Kappa Upsilon National Dental Honor Society.

- Earned a position on Dean's List for High Performance on National Boards Part II

- Earned a position on Dean's List for High Performance on National Boards Part I

- Awarded Tufts Merit Scholarships for 4 consecutive years

- Awarded Research Grant to conduct summer research at Tufts School of Dental Medicine.

- Earned a position on the Dean's list at SAU

- Earned a position on the Dean's list at Texas A\&M

Professional

Experience

Teaching

Experience
2006-Present

- Postgraduate Orthodontic Residency at West Virginia University School of Dentistry.

2005-2006

- General Practice Residency at UMASS Medical School.

Mar-May 2005

- Fabrication Of TMD appliances for Gelb’s TMD Center at Tufts University.

Nov-Dec 2004

- St. Joseph Children Hospital-Dental Externship providing comprehensive dental care to eligible children.

- Tutor in Gross Anatomy and Histology

- Supplemental Instructor in Accounting and Statistics

- Tutor in Mathematics 
Research

Work Experience
Summer 2002 Gelb’s Tempromandibular Joint Disease Center Studying the effect of Level of TMD pain in Treatment acceptance” presented to the Gelb'sTempromandibular Joint Disease Center at Tufts University, Collects data from patients records and analyze statistically the outcome.

$2005 \quad$ Orthodontics Department at Tufts University Immediate effects of various Interocclusal appliances on Temporalis and Masseter Muscle Activity in Different Craniofacial Patterns” research assistant. Recruit subjects, taking impressions and making appliances, cepalometric tracing, data collection and processing.

July 2005-July 2006 UMASS Medical School General Practice Residency Intern

- Providing comprehensive dental care to underserved population of Central Massachusetts in a private clinical setting. Emphasis in Pediatric dentistry, endodontics, Orthodontics, Periodontics, and Oral surgery. Emergency on call in UMass Memorial Hospital.

2002-2005 Tufts Health Science Library

\section{Circulation and Information Assistant}

- Responsible for check in and check out of library materials

- Assist patrons in using the Medline search engine.

2002-2003 Tufts University School of Dental Medicine

\section{Audiovisual assistant}

- Responsible for setting up necessary hardware and software media for lecturers' presentations and seminars

2000-2001 Rehabilitation centers

Sept- Dec 1997 Texas A\&M University

\section{Research Assistant}

- Work for the Chair of Department of Management and Finance at the Business School to collect references and resources for research, organizing and filing information. 